\title{
Evaluation of critical parameters for in vitro skin permeation and penetration studies using animal skin models
}

\author{
Fabíola Silva Garcia Praça ${ }^{\mathrm{a}, *}$, Wanessa Silva Garcia Medina ${ }^{\mathrm{b}}$, Josimar O. Eloy ${ }^{\mathrm{a}, 1}$, Raquel Petrilli ${ }^{\mathrm{a}}$, \\ Patrícia Mazureki Campos ${ }^{\mathrm{a}}$, Andreia Ascenso ${ }^{\mathrm{c}}$, Maria Vitória L.B. Bentley ${ }^{\mathrm{a}}$ \\ a School of Pharmaceutical Sciences of Ribeirão Preto, University of São Paulo, Avenida do Café, s/n, 14040903 Ribeirão Preto, SP, Brazil \\ b Faculdades Integradas Padre Albino - FIPA, Catanduva, SP, Brazil \\ ${ }^{\mathrm{c}}$ Research Institute for Medicines (iMed.ULisboa), Faculdade de Farmácia, University of Lisbon, Portugal
}

\section{A R T I C L E I N F O}

\section{Keywords:}

In vitro skin permeation/penetration study Tape stripping

Micrometric horizontal cryostat skin sectioning Skin source

Frozen/fresh skin

Cryopreservation agent

\begin{abstract}
A B S T R A C T
In vitro skin permeation/penetration studies may be affected by many sources of variation. Herein, we aimed to investigate the major critical procedures of in vitro skin delivery studies. These experiments were performed with model drugs according to official guidelines. The influence of skin source on penetration studies was studied as well as the use of a cryopreservation agent on skin freezing evaluated by transepidermal water loss, electrical resistance, permeation/penetration profiles and histological changes of the skin. The best condition for tape stripping procedure was validated through the evaluation of the distribution of corneocytes, mass of stratum corneum (SC) removed and amount of protein removed using finger pressure, a $2 \mathrm{~kg}$ weight and a roller. The interchangeability of the tape stripping procedures followed by the epidermis and dermis homogenate and the micrometric horizontal cryostat skin sectioning methods were also investigated, besides the effect of different formulations. Noteworthy, different skin sources were able to ensure reliable interchangeability for in vitro permeation studies. Furthermore, an increased penetration was obtained for stored frozen skin compared to fresh skin, even with the addition of a cryoprotectant agent. The best method for tape stripping was the finger pressure followed by the addition of a propylene glycol solvent leading to better SC removal. Finally, no significant difference was found in skin penetration studies performed by different methods suggesting their possible interchangeability.
\end{abstract}

\section{Introduction}

The skin is considered an important route for both topical and systemic administration of drugs. Ideally, topical delivery should be previously tested in vivo in order to study the delivery system, toxicity and irritation potential of unknown drugs, among other parameters (Haigh and Smith, 1994). Despite excised human skin is considered the most appropriate model (gold standard) for in vitro permeation and penetration experiments, some disadvantages lead to use other models. Major drawbacks include poor convenience, difficult obtainment and low standardization level due to variability related to gender, race, age and anatomical site of the donor (Barbero and Frasch, 2009). Thus, herein the use of human skin was avoided and the purpose of this study was to provide a comparison of various animal skin types that could serve as skin membrane models for in-vitro penetration studies. The use of porcine ear skin, hairless mouse skin and shed snake skin has been widely studied as animal model membranes to replace human skin (Vecchia and Bunge, 2005; Itoh et al., 1990a; Itoh et al., 1990b; Rigg and Barry, 1990) as well as to evaluate skin permeation enhancers (Campos et al., 2016; Petrilli et al., 2013; Praça et al., 2012; Baby et al., 2008; Lopes et al., 2007; Nunes et al., 2005; Nicolazzo et al., 2003; Hirvonen et al., 1991), once they are easily available, easy to employ and can provide results rapidly (Jung and Maibach, 2015). Porcine ear skin and hairless mouse skin are widely employed, while shed snake skin has also potential to be used as a membrane model based on stratum corneum (SC) penetration rate (Praça et al., 2012; Baby et al., 2008; Nunes et al., 2005). On the other hand some drawbacks of these alternative membranes should be considered. Porcine ear skin has similar histological characteristics compared to human skin. It presents similar SC thickness and hair-follicle density. However, SC composition

\footnotetext{
* Corresponding author.

E-mail addresses: fgarcia@fcfrp.usp.br (F.S.G.Praça), wasigame@gmail.com (W.S.G. Medina), josimar.eloy@gmail.com (J.O. Eloy), raquelpetrilli@yahoo.com.br (R. Petrilli), patimazureki@hotmail.com (P.M. Campos), andreiaascenso@ff.ul.pt (A. Ascenso), vbentley@usp.br (M.V.L.B. Bentley).

${ }^{1}$ Present address: School of Pharmaceutical Sciences, UNESP - São Paulo State University, Campus Araraquara, Department of Drugs and Medicines, Rodovia Araraquara-Jau, km. 1, Araraquara, São Paulo 14,801-902, Brazil.
} 
of both species differs, because porcine SC presents the lipids organized in hexagonal lattice, whereas human SC is in orthorhombic lattice. Furthermore, in order to obtain this kind of skin it is necessary to have animal slaughterhouse facilities nearby that offer skin in adequate conditions for the experiments. Other hairless mouse species are used and because of the absence of hair, they have similarities with human skin. This model is advantageous because of their small size, low cost and easy handling (Depieri et al., 2015) but one of the major drawbacks is related to increased drug permeation rates compared with human skin, and need for approval of the ethics committee. In the case of snake skin, the samples are obtained without the sacrifice of the animals, are easy to store and do not suffer microbiological deterioration, besides, this model membrane contemplates the aspect of experimental animal ethics and is ecologically correct (Baby et al., 2006). However, this skin is not easy to obtain in a conventional lab and the absence of hair follicles is a disadvantage that limits its use (Godin and Touitou, 2007). Although some studies have already used shed snake skin as a biological membrane for in vitro permeation tests (Baby et al., 2008), there is still a lack of comparative studies that ensure the interchangeability with other animal skins. Thus, the use of porcine ear skin and hairless mouse skin remain the general choice (World Health Organization, 2006).

Furthermore, skin storage is usually required for both in vitro drug permeation and topical drug recovery studies, and consequently, it is quite important that each laboratory defines the most suitable storage conditions (Barbero and Frasch, 2009). Curiously, some authors reported that epithelial membrane previously frozen did not change the permeation profiles of different drugs (Nicolazzo et al., 2003). Conversely, both the permeability and the lag time of hydrophobic drugs were significantly affected by skin freezing (Barbero and Frasch, 2009; Ahlstrom et al., 2007). The use of a cryoprotectant agent such as $10 \%$ glycerol was previously suggested (Liangpeng et al., 2011; Bravo et al., 2000; Richters et al., 1996) in order to avoid ice crystal formation and maintain the skin barrier function. However, there is no consensus yet about the use of a skin cryoprotectant agent and the storage time of frozen skin used for in vitro permeation/penetration studies (Petrilli et al., 2016; Estracanholli et al., 2014; Liangpeng et al., 2011; Barbero and Frasch, 2009).

Different protocols are available to quantify the drug retained into porcine or hairless mouse skins, such as (i) evaluation of drug concentration in SC by the tape stripping technique (Lademann et al., 2009), (ii) evaluation of drug concentration in deeper skin layers by homogenization of skin tissue after tape stripping (viable epidermis without SC and dermis) (Campos et al., 2016; Depieri et al., 2015; Ascenso et al., 2014; Praça et al., 2011), (iii) evaluation of drug concentration in the whole skin tissue by homogenization (Ascenso et al., 2013), and (iv) assessment of skin drug penetration by specific micrometric sectioning of horizontal skin using a cryostat (Praça et al., 2012; Labouta et al., 2011; Echevarria et al., 2003). Among these methods, the homogenization technique of the whole skin tissue is easier, faster and less laborious, being also quite useful to detect a low drug penetration level. Nevertheless, it does not provide data on specific drug skin localization. Tape stripping appears to be simple and easy to perform being useful to assess the distribution and amount of drug in the SC. However, the number of strips and the applied pressure are parameters that should be clearly defined since they may influence the outcome. Some researchers related the uniform pressure on the skin with the amount of SC removed. Protein in corneocytes is the major component of the SC, and this evaluation has been considered a standard technique to quantify the removed SC amount. Meanwhile, the quantification of the penetrated drug in each strip or in the aggregate strips depends on sensitivity of the analytical method. Therefore, most studies quantify the penetrated drug into SC using the aggregate of all tape strips (Campos et al., 2016; Estracanholli et al., 2014; Praça et al., 2011; Rossetti et al., 2010; Herkenne et al., 2006).

Basic knowledge of these underlying critical parameters for skin permeation/penetration studies is an essential aspect for achieving a successful research. An extensive database has been generated over the past years due to numerous in vitro experiments aimed to improve the delivery of topically applied drugs and cosmetics. Nonetheless, few data on the experimental reproducibility based on skin source, skin storage conditions and skin drug recovery rate is available (Praça et al., 2011; Barbero and Frasch, 2009; Lademann et al., 2009; Baby et al., 2008; Ahlstrom et al., 2007; Ngawhirunpat et al., 2006; Baby et al., 2006; Nunes et al., 2005; Löffler et al., 2004; Babu et al., 2003; Takahashi et al., 2001; Pongjanyakul et al., 2000; Haigh et al., 1998; Fang et al., 1995; Hirvonen et al., 1991; Itoh et al., 1990b; Rigg and Barry, 1990; Bronaugh and Stewart, 1985) and none of the studies summarized all these parameters in a single report, which has been addressed herein. Therefore, the main purpose of the present work was to investigate and standardize critical parameters for in vitro skin permeation/penetration studies using animal skin models and thus minimize experimental errors. To our knowledge, this is the first report in which these parameters are correlated.

In order to standardize the protocols for in vitro skin penetration, nicotine, estradiol and fluorescein were used as model drugs and fluorescent probe, respectively. In particular, the specific aims of this work were: (a) to observe the influence of animal skin source on penetration studies; (b) to evaluate the influence of a cryoprotectant agent on skin freezing by transepidermal water loss, electrical resistance, penetration profiles and skin histological changes; (c) to explore the critical parameters involved in drug quantification in different skin layers, such as: the influence of uniform pressure applied in the tape stripping process; the effect of different vehicles composition on tape stripping procedure after in vitro skin permeation, and the interchangeability between the conventional tape stripping followed by epidermis and dermis $(E P+D)$ homogenization and the micrometric horizontal cryostat skin sectioning for the evaluation of skin drug penetration; (d) to evaluate different conditions for nicotine recovery from skin sample.

\section{Materials and methods}

\subsection{Materials}

Nicotine, estradiol and fluorescein (6-carboxylfluorescein) used to prepare standards for HPLC and spectrometric determinations were purchased from Sigma (St. Louis, MO, U.S.A.). Transdermal delivery systems used in this study were Niquitin ${ }^{\mathrm{TM}} 5.1 \mathrm{mg} / \mathrm{cm}^{2}$ (each $15 \mathrm{~cm}^{2}$ contains $78 \mathrm{mg}$ of nicotine) from GlaxoSmithKline (Rio de Janeiro, Brazil) and Estradot ${ }^{\circledR} 0.156 \mathrm{mg} / \mathrm{cm}^{2}$ (each $10 \mathrm{~cm}^{2}$ contains $1.56 \mathrm{mg}$ of estradiol) from Novartis (São Paulo, Brazil). Aqueous solutions were prepared using ultrapure water obtained from a Water Purification System (Millipore Corporation, MA, U.S.A.) and all other reagents or solvents were of analytical or high performance liquid chromatography (HPLC) grade.

\subsection{Methods}

\subsubsection{Comparison of different skin sources on in vitro drug permeation} assay

2.2.1.1. Hairless mouse skin. 6 week old male hairless mouse (HRS/J strain) weighing 20-30 g were obtained from the colony of the School of Pharmaceutical Sciences of Ribeirão Preto (University of São Paulo, Ribeirão Preto, SP, Brazil). They were housed in a temperature and humidity-controlled room, with access to food and water ad libitum. The procedures were approved by the Ethics Committee of the School of Pharmaceutical Science of Ribeirão Preto (University of São Paulo, Ribeirão Preto, SP, Brazil - Process \#09.1.505.53.6).

2.2.1.2. Porcine ear skin. Porcine ear skin samples obtained from a local slaughterhouse were carefully dissected (ensuring that the 
subcutaneous fat was completely removed), and dermatomed with a thickness of $500 \mu \mathrm{m}$ (Dermaton, Nouvag, Switzerland). Skin samples were immediately used or frozen with or without a cryoprotectant agent.

2.2.1.3. Shed snake skin. Ventral portions of shed snake skin were obtained from Crotalus durissus terrificus (rattlesnake) aged approximately 2 years old as a courtesy of Central Captivity of Faculty of Ribeirão Preto, University of São Paulo, SP, Brazil. The skin was washed with distilled water at room temperature $\left(25.0 \pm 2.0^{\circ} \mathrm{C}\right)$ and dried with filter paper. The skin samples were carefully stored at $25{ }^{\circ} \mathrm{C}$ and $60 \%$ humidity being protected from light for 30 days before use. Before the permeation studies, the snake skin samples were treated using a mechanical removal technique by tape stripping applied once with adhesive tape (Scotch, 3M) as previously reported by Baby et al. (2008). Then, the skin samples were fully hydrated for 12 or $24 \mathrm{~h}$.

2.2.1.4. In vitro permeation studies. On the day of the experiment, all tissues (hairless mouse skin, porcine ear skin and hydrated snake skin) were mounted in static Franz diffusion cells with a diffusion area of $1.77 \mathrm{~cm}^{2}$ (Hanson Instruments, Chatsworth, CA) (Baby et al., 2008; Lopes et al., 2007). Commercial transdermal nicotine, Niquitin ${ }^{\text {TM }}$ $\left(5,1 \mathrm{mg} / \mathrm{cm}^{2}\right)$, or transdermal estradiol, Estradot ${ }^{\circledR}\left(0.156 \mathrm{mg} / \mathrm{cm}^{2}\right)$, were placed on the donor compartment and the receptor compartment was filled with $100 \mathrm{mM}$ phosphate buffer ( $\mathrm{pH} 7.2$ ) containing or not $2 \%$ of Tween surfactant, stirred at $400 \mathrm{rpm}$ and maintained at $32{ }^{\circ} \mathrm{C}$ in a water bath. After 1, 2, 3, 4, 6 and $8 \mathrm{~h}$, samples $(1 \mathrm{~mL})$ were collected from the receptor compartment to measure the amount of permeated nicotine or estradiol. The same volume of receptor phase was carefully replaced. The total amount of nicotine or estradiol that permeated through the different skin types were analyzed by HPLC methods previously reported by our research group (De Paula et al., 2007; Pereira et al., 2001) using a Shimadzu system (Kyoto, Japan) with UV-visible (UV-vis), Lichrospher ${ }^{\circledR} 60$ RP-18 (12.5 cm length, $5 \mu \mathrm{m}, 4 \mathrm{~mm}$ Select B (Merck, Darmstadt, Germany) as chromatographic column and UV detector at 245 or $280 \mathrm{~nm}$ for nicotine and estradiol quantification, respectively. For nicotine, the isocratic mobile phase was composed of water: methanol: $0.1 \mathrm{M}$ buffer acetate (pH 4.5): acetonitrile: acetic acid (74:3:20:2:1, v/v/v/v) adjusted to $\mathrm{pH} 4.2$ with diethylamine, and then degassed with helium gas. The flow rate of mobile phase was $0.8 \mathrm{~mL} / \mathrm{min}$ at $35^{\circ} \mathrm{C}$ and the injection volume was $20 \mu \mathrm{L}$ (Pereira et al., 2001). For estradiol, the mobile phase was an isocratic acetonitrile: water (50:50), degassed with helium gas, with flow rate of $1.0 \mathrm{~mL} / \mathrm{min}$ at $60^{\circ} \mathrm{C}$ and injection volume of $20 \mu \mathrm{L}$ (De Paula et al., 2007). The standard curves were linear from 0.5 to $100 \mu \mathrm{g} /$ $\mathrm{mL}$ and 5.0 to $50 \mu \mathrm{g} / \mathrm{mL}$ for nicotine and estradiol, respectively, showing linear correlation coefficient $(r)>0.99$ and $\mathrm{CV} \%$ values lower than $10 \%$. Detection and quantification limits were, respectively, 0.05 and $0.1 \mu \mathrm{g} / \mathrm{mL}$ for nicotine and 0.5 and $1.0 \mu \mathrm{g} / \mathrm{mL}$ for estradiol.

2.3. Influence of skin preparation methods and storage conditions on the penetration studies using a porcine ear skin model

\subsubsection{Porcine ear skin usage conditions}

(i) Fresh

Porcine ear skin was prepared as described in 2.1.1.2 item. This skin was immediately used avoiding storage and/or freezing process.

\section{(ii) Frozen without cryoprotectant agent}

Fresh skin samples were wrapped in aluminum foil, placed in polyethylene bags and stored at $-20{ }^{\circ} \mathrm{C}$ for 15 and 30 days.

\section{(iii) Frozen with glycerol (cryopreserved skin)}

The glycerol-cryopreservation protocol was performed based on Bravo et al., 2000. Fresh skin samples were submerged in Petri dishes containing $10 \%$ glycerol in saline solution and incubated for $40 \mathrm{~min}$ at room temperature (Bravo et al., 2000). Then, skin samples were dried with a soft paper and wrapped in aluminum foil, placed in polyethylene bags and stored at $-20^{\circ} \mathrm{C}$ for 15 and 30 days. Afterwards, the samples were thawed and rehydrated with purified water for $5 \mathrm{~min}$ before the experiments. This step allowed removal of the remaining glycerol in the skin.

\subsubsection{Transepidermal water loss (TEWL) and electrical skin resistance}

Skin samples stored at different conditions were evaluated regarding the transepidermal water loss (TEWL) and electrical resistance by using a tewameter (TM 210, Köln, Germany) and Agilent 33220A (Waveform generator, USA) equipments, respectively. The TEWL values were measured every $30 \mathrm{~s}$ over $2.5 \mathrm{~min}$. The electrical resistance values across skin membrane were measured using a setting of $10 \mathrm{~Hz}$ and $100 \mathrm{mV}$ rms. The electrical resistance of the skin was then calculated from Ohm's law. The minimum initial skin resistance of fresh skin was set at $35 \mathrm{k} \Omega . \mathrm{cm}^{2}$, otherwise skin samples were discarded (Tang et al., 2001).

\subsubsection{Qualitative and quantitative skin freezing effects on in vitro skin permeation/penetration studies}

Fresh and frozen skin samples were mounted on vertical Franz diffusion cells (Microette system, Hanson Research Corporation, Chatsworth, CA) with a diffusion area of $1.77 \mathrm{~cm}^{2}$. The receptor compartment $(7 \mathrm{~mL})$ was filled with $100 \mathrm{mM}$ phosphate buffer $\mathrm{pH} 7.4$ which was stirred at $400 \mathrm{rpm}$ and maintained at $32{ }^{\circ} \mathrm{C}$, as mentioned before. In order to evaluate the in vitro skin penetration, $200 \mu \mathrm{L}$ of hydrophilic sodium fluorescein aqueous solution $(0.4 \mathrm{mg} / \mathrm{mL})$ was applied on skin samples for qualitative and quantitative assays. At $24 \mathrm{~h}$ post application of fluorescein solution, the skin samples were removed from the vertical Franz diffusion cells and washed with distilled water. For qualitative evaluation, diffusion areas of skin were frozen in Tissue$\mathrm{Tek}^{\oplus}$ (Pelco International, Redding, CA, USA) using acetone at $-30{ }^{\circ} \mathrm{C}$ and sectioned at $-20^{\circ} \mathrm{C}$ by a cryostat microtome (Leica, Wetzlar, Germany) into $20 \mu \mathrm{m}$ slices and finally mounted on glass slides. The slices were analyzed in order to verify the intensity and depth of sodium fluorescein penetration into skin layers using a fluorescence microscope (Axioshop 2 plus, Carl Zeiss, Germany) equipped with $640 \mathrm{~nm}$ and $730 \mathrm{~nm}$ band-pass excitation and emission filters and AxioVision software. Identical sensitivity and exposure settings were used for all samples (Praça et al., 2012). For quantitative assay, $1.0 \mathrm{~mL}$ was sampled from the receptor solution to determine the total amount of sodium fluorescein permeated through the skin by the end of the experiment using a spectrophotometer (FentoScan, Brazil) at $490 \mathrm{~nm}$ (Gould, 2016).

\subsubsection{Histological assessment}

Histological measurements were carried out with hematoxylin and eosin ( $\mathrm{H} \& \mathrm{E}$ ) and examined under a light microscope (Axioplan 2 Image Pol microscope, Carl Zeiss, Germany). Possible histological changes promoted by freezing storage procedure were observed and compared with the control (fresh skin) using $400 \times$ magnification.

2.4. Comparison of conventional tape stripping followed by $E P+D$ (epidermis plus dermis without EC) homogenization process and horizontal skin sectioning technique using a cryostat

\subsubsection{Tape stripping validation}

The adhesive tape (Scotch ${ }^{\circledR} ; 3 \mathrm{M}$, S. Paulo, Brazil, precut $2.0 \mathrm{~cm}$ ) was pressed onto the skin by three different protocols, such as: (i) protocol A - using a roller to stretch the skin surface; (ii) protocol B - using a 
constant $2 \mathrm{~kg}$ cylindrical weight applied on the skin surface for a defined period ( $30 \mathrm{~s}$ per each tape before removal) resulting in a pressure of $349.3 \mathrm{~g} / \mathrm{cm}^{2}$ (Ascenso et al., 2015), and (iii) protocol C - using the operator finger pressure applied 3 times on each adhesive tape before removing it from the skin. All protocols were carried out using porcine ear skin as biological membrane followed by 20 adhesive tapes consecutively applied and quickly removed. These procedures were always conducted by the same operator in order to minimize variations. The homogeneity of corneocytes distribution on the strips, the mass of SC removed and the amount of protein removed by the different procedures were compared.

\subsubsection{Homogeneity of corneocytes distribution on the strip}

The tape strips were successively applied on the skin using protocols A to $\mathrm{C}$, and then, each one was applied on microscope slides. The homogeneity of corneocytes removed by individual adhesive tape strips was observed by microscopy using a Zeiss microscope (Axio Imager A.1, Carl Zeiss, Germany) equipped with AxioVision software. The observations were performed using $200 \times$ magnification.

\subsubsection{Mass of SC removed}

To estimate the mass of the SC removed by 20 adhesive tapes using protocols A, B and C, each tape was weighed prior to the application onto the skin and after skin removal.

\subsubsection{Amount of protein removed by individual adhesive tapes}

The amount of protein removed by tape stripping procedures using protocols A, B and C was compared as well. Each striped tape was transferred to an eppendorf tube with $2 \mathrm{~mL}$ of methanol and vortexed for $2 \mathrm{~min}$. Measurements of protein absorption were obtained using a UV-Spectrometer at $278 \mathrm{~nm}$, according to a previously reported method (Lindemann et al., 2003).

\subsubsection{Effect of different vehicles on tape stripping after $24 \mathrm{~h}$ of in vitro permeation studies}

The influence of both hydrophilic and less hydrophilic vehicles applied on the skin (donor compartment of diffusion cell), such as sodium phosphate buffer and propylene glycol, on the tape stripping procedure was evaluated. After $24 \mathrm{~h}$ of permeation study, the skin samples were removed from the Franz diffusion cells, carefully dried with absorbent paper, and followed by tape stripping procedure applied with the finger pressure (a) immediately and (b) $1 \mathrm{~h}$ after the end of permeation study. Individual stripped tapes were applied on microscope slides and the amount of SC removed was macroscopically observed.

\subsubsection{Epidermis (without $S C$ ) and dermis $(E P+D)$ homogenization process}

After $24 \mathrm{~h}$ of permeation study already described in 2.1.2 item, the skin samples were removed from vertical Franz diffusion cells and the skin surfaces were carefully washed with running water. Then, the diffusion area of the skin samples was tape stripped using finger pressure to remove the SC and the remaining skin sections $(\mathrm{EP}+\mathrm{D})$ were cut into small pieces, put in glass tubes and kept for extraction. Finger pressure on tape stripping process was selected considering the promising results obtained on validation tape stripping process (2.3.1 item).

2.4.6.1. Nicotine extraction from skin samples. Nicotine skin extraction procedure was performed using a validated method, comparing different conditions, such as extraction solvents (methanol, phosphate buffer and acetonitrile), ultrasound water bath time (15 or $30 \mathrm{~min}$ ), and the influence of Ultra Turrax ${ }^{\circledR}$ tissue cutter was also considered (Marconi, Brazil). Ultra Turrax ${ }^{\circledR}$ tissue cutter was used prior to the ultrasound bath to assess whether it would be able to improve the recovery rate of nicotine from $\mathrm{EP}+\mathrm{D}$.
Briefly, $20 \mu \mathrm{L}$ of a nicotine methanolic solution $(1000 \mu \mathrm{g} / \mathrm{mL})$ was carefully added to the skin (EP $+\mathrm{D})$ avoiding the contact with the glass tube. After a drying step by flow air, the amount of drug retained in the skin was extracted using different conditions, such as $4 \mathrm{~mL}$ of methanol or acetonitrile or $100 \mathrm{mM}$ phosphate buffer ( $\mathrm{pH} 7.4$ ), stirred for $2 \mathrm{~min}$, homogenized or not by Ultra Turrax ${ }^{\circledR}$ at $2500 \mathrm{rpm}$, and maintained at ultrasound water bath for 15 or $30 \mathrm{~min}$. The resultant mixtures were then filtered through a $0.45 \mu \mathrm{m}$ pore size membrane (Sartorius, Goettingen, Germany), and nicotine concentration was assessed by the validated HPLC method.

The methodology that showed higher rates of nicotine recovery from EP + D sample was selected for comparative drug recovery studies with the horizontal skin sectioning cryostat technique.

\subsubsection{Micrometric horizontal cryostat sectioning of the whole skin}

After $24 \mathrm{~h}$ of the permeation study described in 2.1.2 item, the diffusion areas of skin samples were frozen in Tissue-Tek (Pelco International, Redding, CA, USA) using acetone at $-30{ }^{\circ} \mathrm{C}$ and sectioned by a cryostat microtome (Leica, Wetzlar, Germany). Then, the extraction of the retained nicotine in the sectioned tissue was performed. Each horizontal skin sections $(40 \mu \mathrm{m})$ were individually transferred to vials glass tubes containing $1 \mathrm{~mL}$ of $100 \mathrm{mM}$ phosphate buffer ( $\mathrm{pH}$ 7.4). All samples were maintained in ultrasound water bath for $15 \mathrm{~min}$ and vortexed for $1 \mathrm{~min}$ before the assessment of nicotine amount by HPLC. These results were compared with those obtained by conventional tape stripping using finger pressure followed by EP + D homogenization process. The amount of nicotine measured in each skin fraction $(40 \mu \mathrm{m})$ was defined for three groups, such as SC (accumulated amounts of nicotine measured in skin layers ranged from 0 to $40 \mu \mathrm{m}$ ), $\mathrm{EP}+\mathrm{D}$ (accumulated amounts of nicotine measured in layers ranged from 41 to $400 \mu \mathrm{m}$ ) and total skin (the sum of nicotine amounts measured in layers ranged from 0 to $400 \mu \mathrm{m}$ ), as previously described by Echevarria et al. (2003).

\subsection{Statistical analysis}

The results were expressed as mean \pm standard deviation (SD) and analyzed using GraphPad Prism ${ }^{\circledast}$ software. Data were statistically analyzed by one-way ANOVA followed by Tukey multiple comparison test to compare more than two experimental groups and Student's T unpaired test to compare two experimental groups. The level of significance was set as $p<0.05$.

\section{Results}

\subsection{Influence of the skin source}

Typical Brazilian snake skin (Crotalus durissus terrificus) was compared with porcine ear skin and hairless mouse skin for the in vitro permeation study using nicotine and estradiol transdermal patches. Our results demonstrated a relatively similar permeation profile for different skin sources (Fig. 1). Considering the requirement of shed snake skin pretreatment (Baby et al., 2007; Baby et al., 2006), this skin was previously hydrated for 12 and $24 \mathrm{~h}$ before the permeation studies. In fact, the hydration of shed snake skin for $24 \mathrm{~h}$ was able to increase the nicotine flux 5-fold compared to 12-h hydration resulting in flux values of 342.8 and $65 \mu \mathrm{g} / \mathrm{cm}^{2} / \mathrm{h}^{-1}$, respectively (data not shown). Furthermore, no significant differences were observed for hairless mouse, porcine ear skin and snake skin regarding the nicotine flux (data shown in Fig. 1) and the accumulated amount of nicotine permeated through the skin after $8 \mathrm{~h}$ was equivalent to 5176 ( \pm 121$)$; 5246 ( \pm 778 ) and $5489( \pm 271) \mu \mathrm{g} / \mathrm{cm}^{2}$, respectively (Fig. 1A). When estradiol was used as lipophilic drug model, a similar result was obtained. The amount of estradiol permeated through the skin after $8 \mathrm{~h}$ was equivalent to 37.16 $( \pm 2.7), 36.15( \pm 5.0)$ and $40.89( \pm 3.0) \mu \mathrm{g} / \mathrm{cm}^{2}$ and flux $(J)$ was $3.71,3.70$ and $4.00 \mu \mathrm{g} / \mathrm{cm}^{2} / \mathrm{h}$ for porcine ear skin, hairless mouse and 
(A)

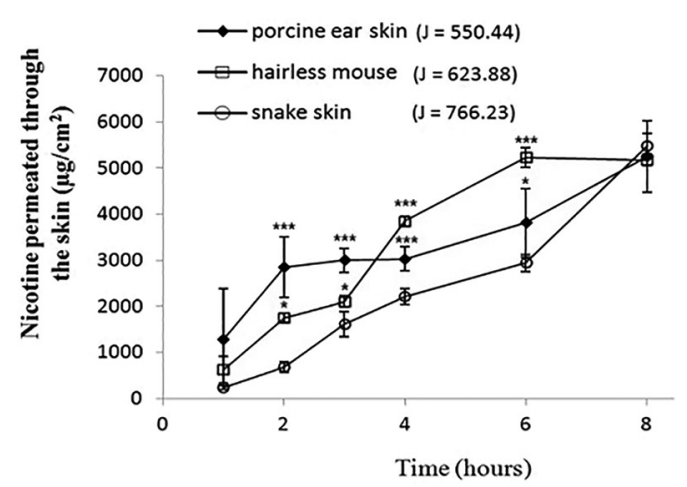

(B)

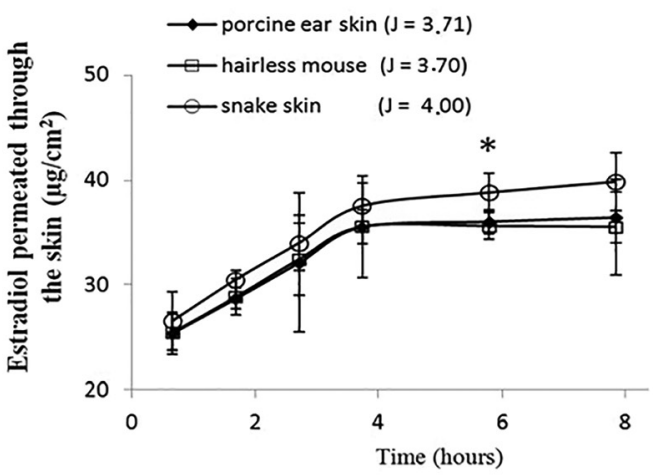

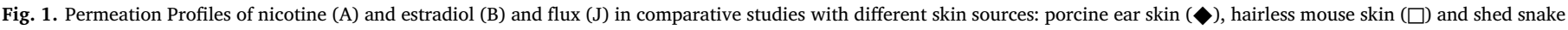

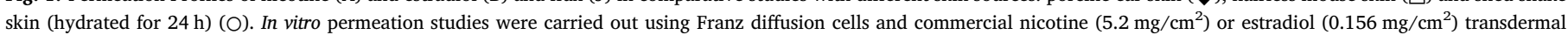

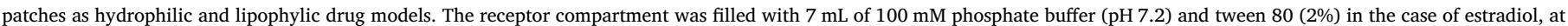

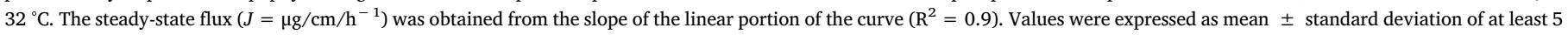
experiments. The statistical one-way ANOVA followed by Tukey multiple comparison test was applied $(p<0.05)$ compared with snake skin.

snake skin, respectively. Thus, these three animal biological membranes sources may be all used as skin sources for in vitro permeation studies of either lipophilic and hydrophilic drugs.

\subsection{Influence of skin storage}

For the skin storage study, we used fluorescein, a fluorescent dye which allowed the observation of porcine ear skin penetration. In addition, the epithelial membrane changes promoted by freezing process were qualitatively and quantitatively analyzed as illustrated in Fig. 2. According to the photomicrographs, it was possible to observe typical characteristics of skin such as the presence of a thick SC, an epidermis containing with many cell layers and disorderly organized collagen fibers. However, some parts of the epidermis shrank when frozen skin was used (Fig. 2- B to E). Transepidermal water loss (TEWL) and electrical resistance corresponded to $7 \mathrm{~g} / \mathrm{m}^{2} / \mathrm{h}$ and 35 to $40 \mathrm{k} \Omega \cdot \mathrm{cm}^{2}$
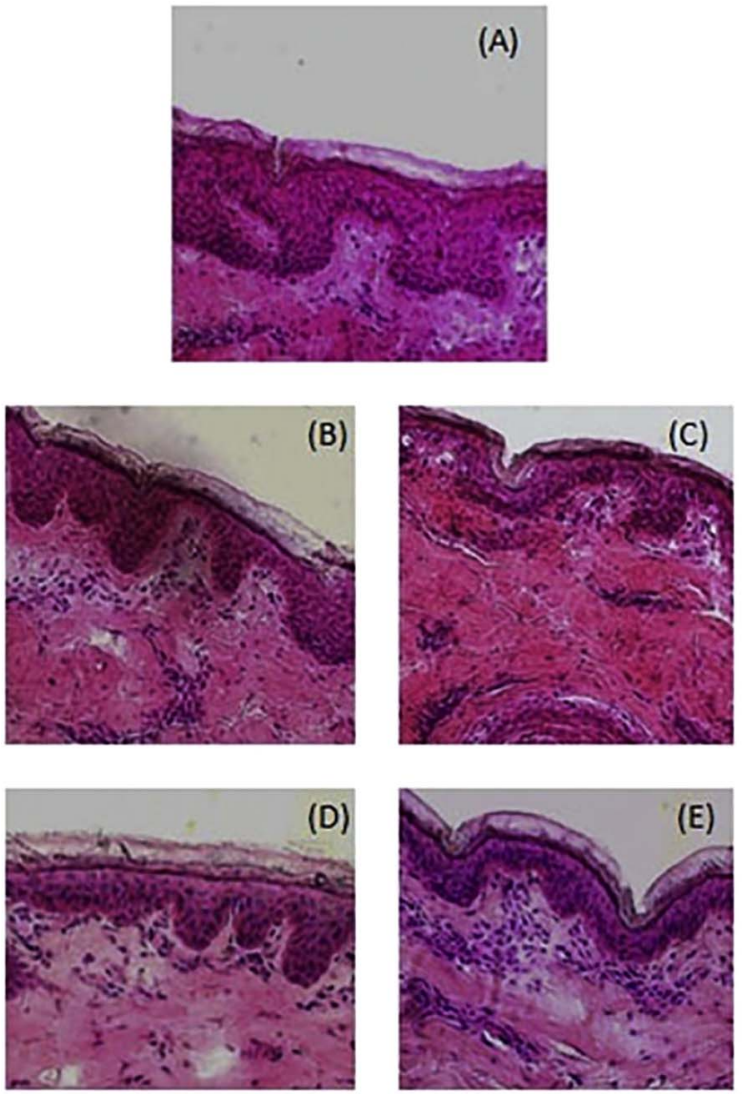

(F)

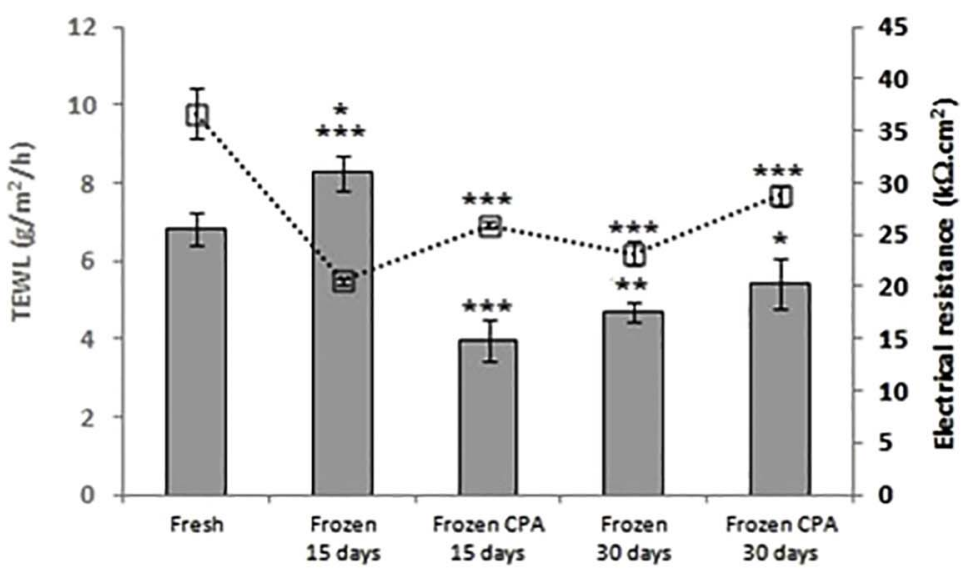

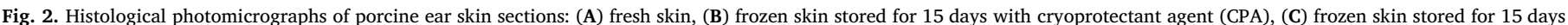

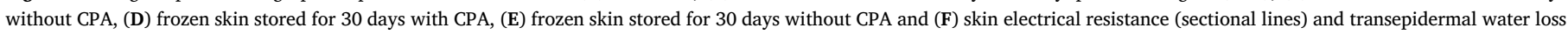

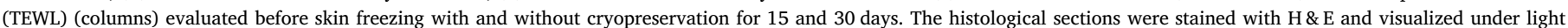

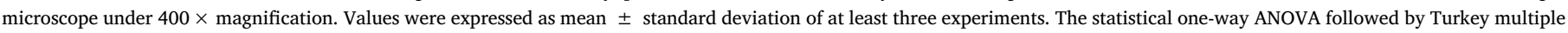
comparison test was applied ( $p<0.05$ ) compared with the control (fresh skin). 

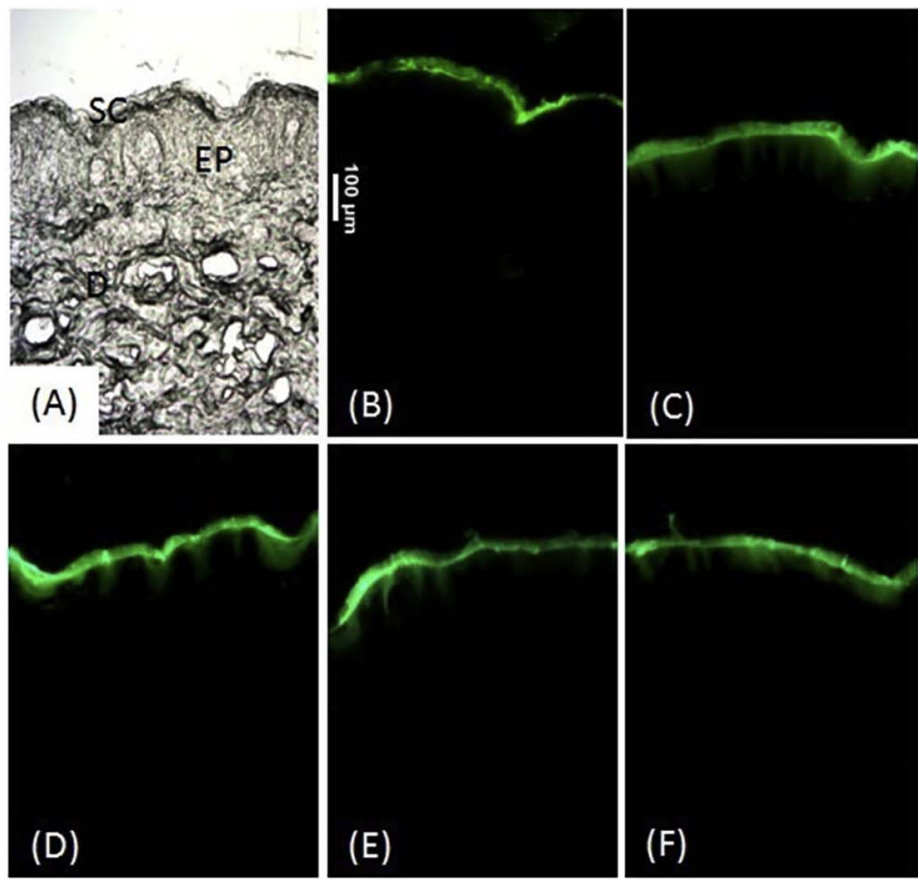

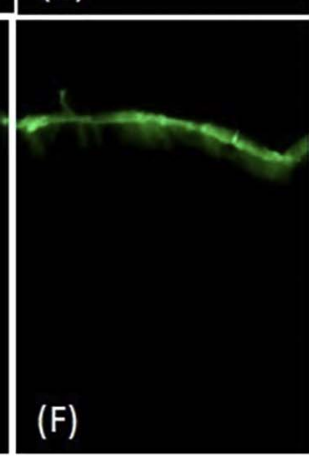

\section{( $\mathbf{G})$}

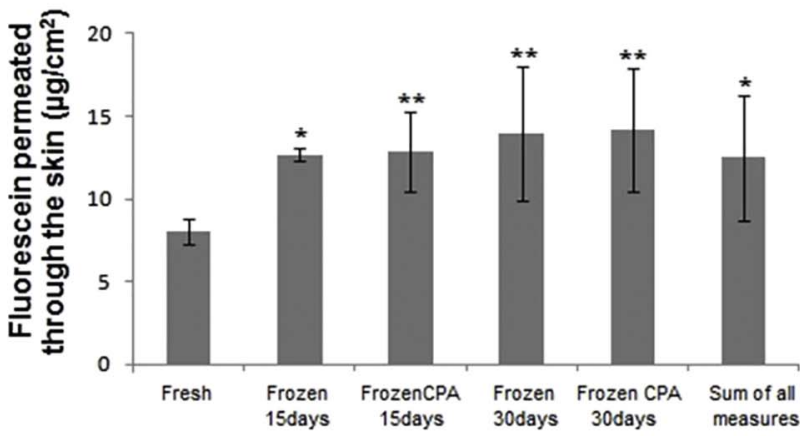

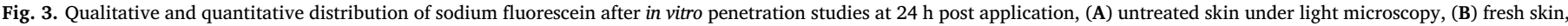

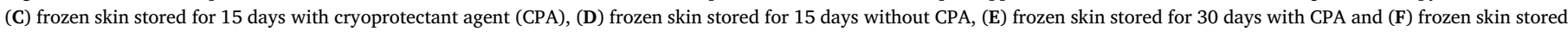

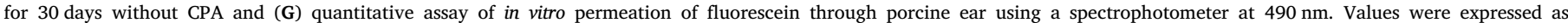

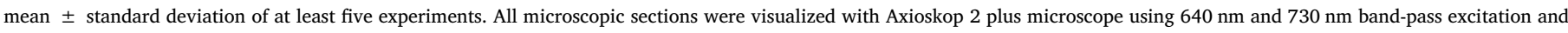

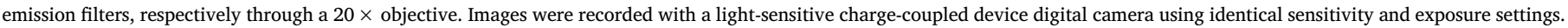
The statistical one-way ANOVA followed by Tukey multiple comparison test was applied $(p<0.05)$ compared with the control (fresh skin).

for fresh skin and 4 to $8 \mathrm{~g} / \mathrm{m}^{2} / \mathrm{h}$ and 20 to $28 \mathrm{k} \Omega \cdot \mathrm{cm}^{2}$ for frozen skin, respectively (Fig. 2-F). These quantitative evaluations presented significant statistical differences. Thereby, the freezing process with or without a cryoprotectant agent can change histological features, TEWL and electrical resistance, indicating skin damage compared to fresh skin.

The permeation and penetration of fluorescein through fresh and frozen skin was also demonstrated in Fig. 3. Fig. 3-C to F showed strong fluorescence intensity in SC and deeper layers for all skins used, except for fresh skin (Fig. 3-B) in which the fluorescence intensity was predominantly present in the SC. Quantitative analysis of fluorescein permeation through fresh and frozen skin samples corresponded to $8 \mu \mathrm{g} / \mathrm{cm}^{2}$ and 12 to $14 \mu \mathrm{g} / \mathrm{cm}^{2}$, respectively (Fig. 3-G). These results represent a significantly increased permeation through frozen skin about 2.0-fold higher at $24 \mathrm{~h}$. Moreover, a lower error measurement (coefficient of variation) was observed for fresh skin (16\%) compared to frozen skin (30\%), when all obtained results were treated as a single experiment $(n=15)$.

\subsection{Tape stripping process followed by $E P+D$ homogenization method and comparison with cryostat skin sectioning method}

Regarding the tape stripping process, Fig. 4-A showed that there was a minimal difference of SC amount removed on the 1st and 10th strips when we compared the different protocols employed for tape stripping, using the finger pressure, a $2 \mathrm{~kg}$ cylindrical weight and a roller on strips. However, it was possible to remove a higher amount of corneocytes on the 1st strip. Furthermore, the 20th strip showed a lower $\mathrm{SC}$ amount especially when finger pressure process was employed, indicating that this technique could be more suitable for the complete SC removal. In general, the mass of removed SC as a function of tape strips number revealed a similar pattern for all pressure procedures and decreased proportionally with tape strips number (Fig. 4-B). These findings are in accordance with protein content results in removed tapes from the skin samples, following the same order: finger pressure $>$ constant weight $>$ roller (Fig. 4-C and D).

The amount of SC removed by tape stripping technique can be influenced by the degree of skin hydration (European Medicines Agency, 2014; Baby et al., 2008; OECD, 2004). In this case, we observed the removal of skin parts of the epidermal layer (Fig. 5-A, 7th tape) when tape stripping was performed immediately after the end of the experiment with a hydrophilic vehicle (sodium phosphate buffer). However, the bench time of $1 \mathrm{~h}$ after this experiment was not necessary when a less hydrophilic vehicle (propylene glycol) was used. The presence of propylene glycol on the skin might have increased the cohesion between the corneocytes, and SC was only removed after 10 adhesives tapes (Fig. 5-C).

In order to compare the conventional tape stripping followed by EP $+\mathrm{D}$ homogenization process and the cryostat skin sectioning for the extraction of nicotine from skin samples, a previously developed methodology was used to optimize the extraction efficiency. The optimum extraction methodology for nicotine recovered from EP + D was obtained when $4 \mathrm{~mL}$ of $100 \mathrm{mM}$ phosphate buffer (pH 7.4) or acetonitrile were used as extraction solvents followed by tissue cutter (ultra turrax) at $2500 \mathrm{rpm}$ for $2 \mathrm{~min}$, incubated at ultrasound water bath for $30 \mathrm{~min}$ and filtered through $0.45 \mu \mathrm{m}$ pore membrane. These optimal parameters allowed $90 \%$ of nicotine recovery from skin (Table 1 ). The use of tissue cutter improved the nicotine extraction from $76 \%$ to $90 \%$. The same extraction methodology (but without tissue cutter) was applied for SC samples, and 98\% nicotine was recovered.

In Fig. 6-A the micrometric horizontal skin cryostat sectioning from dermatomed skin $(\mathrm{SC}+\mathrm{EP}+\mathrm{D})$ was used to quantify nicotine in different skin layers, and Fig. 6-B shows the conventional tape stripping followed by EP + D homogenization procedure. Regarding the study with horizontal sectioning, the first skin fraction $(40 \mu \mathrm{m})$ corresponded to the SC layer. However, amounts of SC can be also present in sections from 41 to $400 \mu \mathrm{m}$ corresponding to $\mathrm{EP}+\mathrm{D}$. In this range, 280 and $220 \mu \mathrm{g} / \mathrm{cm}^{2}$ of nicotine retained into EP $+\mathrm{D}$ were obtained from 
(A)

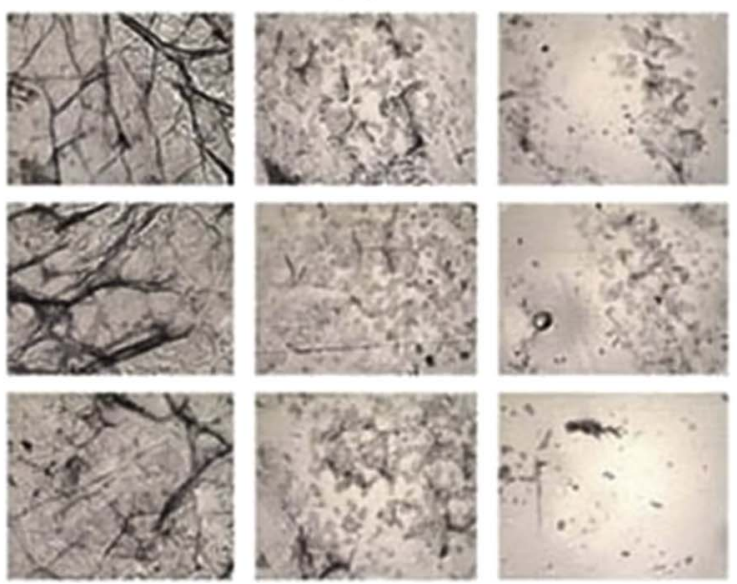

(C)

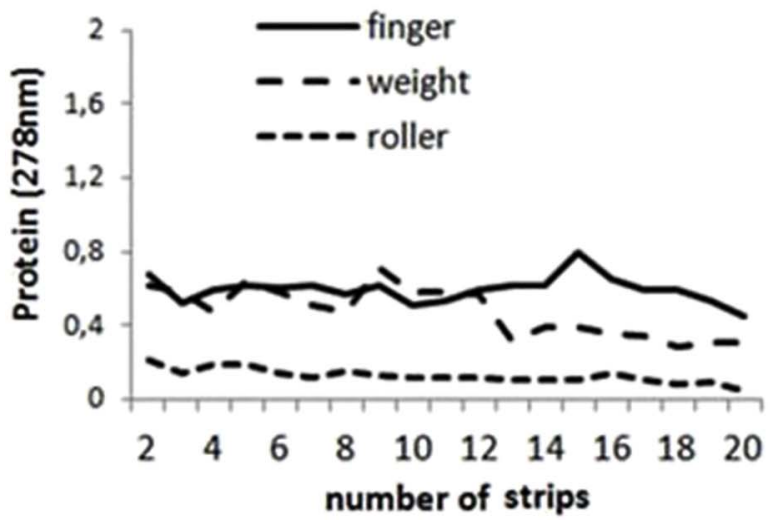

(B)

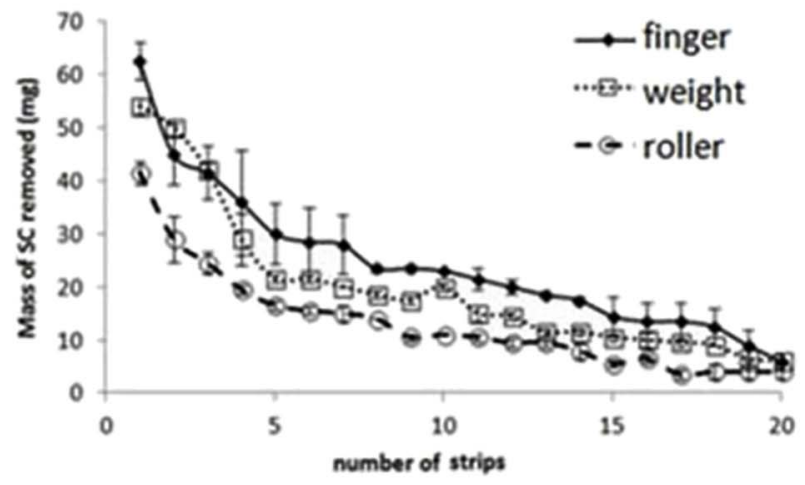

(D)

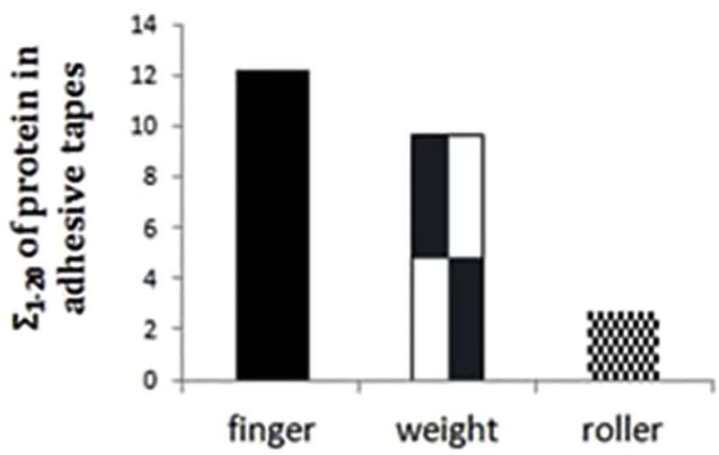

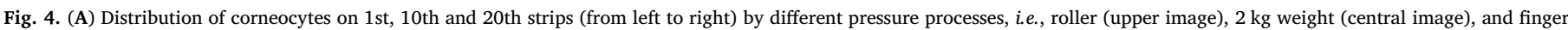

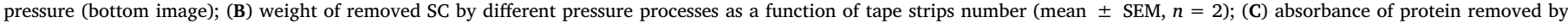

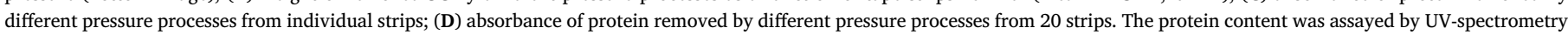
at $278 \mathrm{~nm}$.

(A)
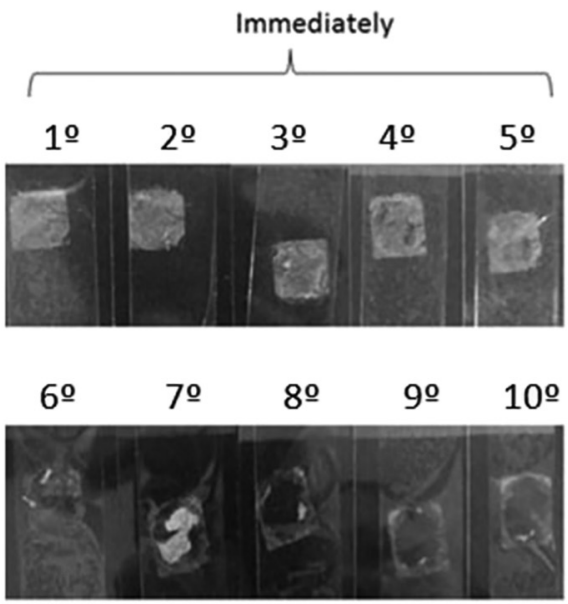

(B)
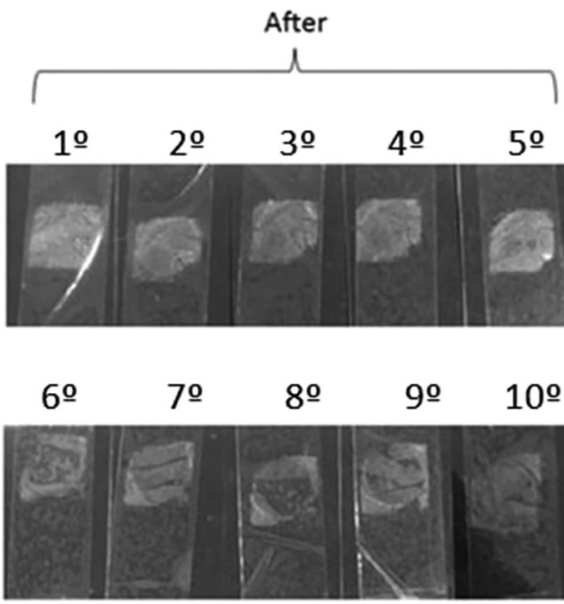

(C)
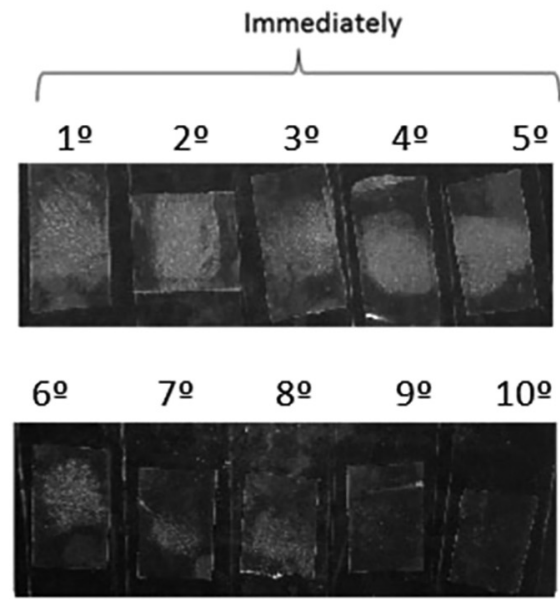

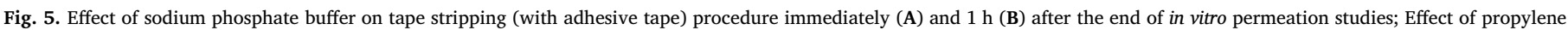

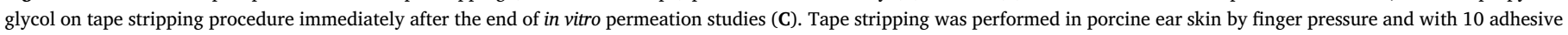
tapes. 
Table 1

Nicotine recovery from skin using different extraction procedures.

\begin{tabular}{|c|c|c|c|c|c|c|c|c|c|c|c|c|}
\hline \multirow{3}{*}{$\begin{array}{l}\text { Extraction solvent ( } 4 \mathrm{~mL} \text { ) } \\
\text { Ultrasound water bath } \\
\text { Tissue cutter }\end{array}$} & \multicolumn{4}{|c|}{ Methanol } & \multicolumn{4}{|c|}{ Acetonitrile } & \multicolumn{4}{|c|}{100 mM phosphate buffer (pH 7.4) } \\
\hline & $15 \mathrm{~min}$. & & $30 \mathrm{~min}$. & & $15 \mathrm{~min}$. & & $30 \mathrm{~min}$. & & $15 \mathrm{~min}$. & & $30 \mathrm{~min}$. & \\
\hline & $2 \mathrm{~min}$ & - & $2 \mathrm{~min}$. & - & $2 \mathrm{~min}$. & - & $2 \mathrm{~min}$ & - & $2 \mathrm{~min}$. & - & $2 \mathrm{~min}$ & - \\
\hline Nicotine skin recovery (\%) & 89.4 & 76.9 & 88.3 & 80.3 & 87.7 & 78.4 & 91.3 & 80.7 & 88.0 & 72.1 & 90.4 & 75.6 \\
\hline
\end{tabular}

conventional tape stripping followed by EP + D homogenization and micrometric horizontal skin cryostat sectioning methods, respectively. In addition, approximately 35,280 and $315 \mu \mathrm{g} / \mathrm{cm}^{2}$ of nicotine was retained into the SC, EP + D and total skin ( $500 \mu \mathrm{m}$ thickness), respectively using the conventional skin treatment. However, the total nicotine amount recovered from $400 \mu \mathrm{m}$ skin was $250 \mu \mathrm{g} / \mathrm{cm}^{2}$ in the other process. Considering the ratio between nicotine recovered $(\mu \mathrm{g} /$ $\mathrm{cm}^{2}$ ) and the thickness of the skin assessed $(\mu \mathrm{m})$, there was no significance difference for both protocols of drug recovery. In particular, 0.630 and $0.625 \mu \mathrm{g} / \mathrm{cm}^{2} / \mu \mathrm{m}$ of nicotine were observed for the conventional tape stripping followed $\mathrm{EP}+\mathrm{D}$ homogenization and micrometric horizontal skin cryostat sectioning, respectively.

\section{Discussion}

In this work, nicotine and estradiol were chosen since they are wellknown percutaneous drug models due to their favorable physicochemical characteristics for skin permeation, related to their physicochemical characteristics. The porcine ear skin is considered an excellent animal model in many fields of biomedical research (Meurens et al., 2012) and has become increasingly important in the past twenty years as a model to study skin drug delivery (Herron and DVM, 2009; Summerfield et al., 2015). Indeed its skin anatomy shares numerous similarities with the human skin, as opposed to the snake and mouse skins (Debeer et al., 2013), in terms of general structure, thickness, hair follicle content, pigmentation, collagen and lipid composition (Mahl et al., 2006). Previously, it has been reported that human skin stratum corneum thickness ( 20 to $26 \mu \mathrm{m}$ ) is comparable to what is observed in porcine ear skin, while complete human epidermis varies from 50 to $120 \mu \mathrm{m}$ in thickness compared to 30 to $140 \mu \mathrm{m}$ in porcine ear skin (Summerfield et al., 2015). The skin penetration of several compounds has been found to be similar when porcine and human skins were compared (Barbero and Frasch, 2009; Mahl et al., 2006). Besides, low intra- and inter-variations were evident for different substances after in vitro permeation studies using porcine skin in comparison with human skin (Qvist et al., 2000). From these findings it may be concluded that porcine ear skin is a good alternative to human skin and therefore herein we employed porcine ear skin in comparison with other animal skins for in-vitro penetration studies.

Thereafter, we performed the permeation studies with porcine ear skin, hairless mouse skin and snake skin (Baby et al., 2008; Nunes et al., 2005; Nicolazzo et al., 2003). For the study with the snake skin, we selected the ventral regions of theskin, as suggested by Haigh et al. (1998), who observed that the ventral layer is a thicker and resistant layer since it is always in contact with surfaces. On the contrary, the dorsal region of the snake skin is thinner and presents different diffusion rates (Haigh et al., 1998; Takahashi et al., 2001). We observed that the pretreatment of snake skin by hydration at different periods (12 and $24 \mathrm{~h})$ has influenced nicotine permeation rates. Accordingly, the amount of nicotine permeated through the skin and flux values $(J)$ were proportional to the increase of skin hydration time, as expected. In fact, hydrated skin is more permeable than dried skin because the SC is a dynamic structure, in which extended hydration ( $>8 \mathrm{~h}$ ) swells corneocytes, creates reversible intercorneocyte ruptures, and causes microstructural changes in lipid self-assembly (Tan et al., 2010). In this case, snake skin requires longer time of cutaneous hydration due to the lack of follicles. Thus, snake skin hydrated for $24 \mathrm{~h}$ was selected for comparative in vitro nicotine permeation.

An interesting observation from comparative in vitro permeation studies was the large deviation regarding all sampling times for porcine ear skin (Fig. 1). This could be correlated with the difficulty on controlling age, gender and feeding of animals as well as the sample preparation of porcine ear skin required before the dermatomization process for permeation studies. On the contrary, these parameters were monitored for shed snake and hairless mouse skins, contributing to a significant reproducibility of the results. Nevertheless, the porcine ear skin and the hairless mouse skin are both popularly used skin models among research community and have been established as reliable
(A)

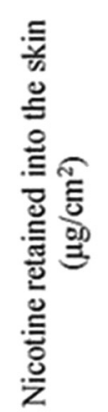

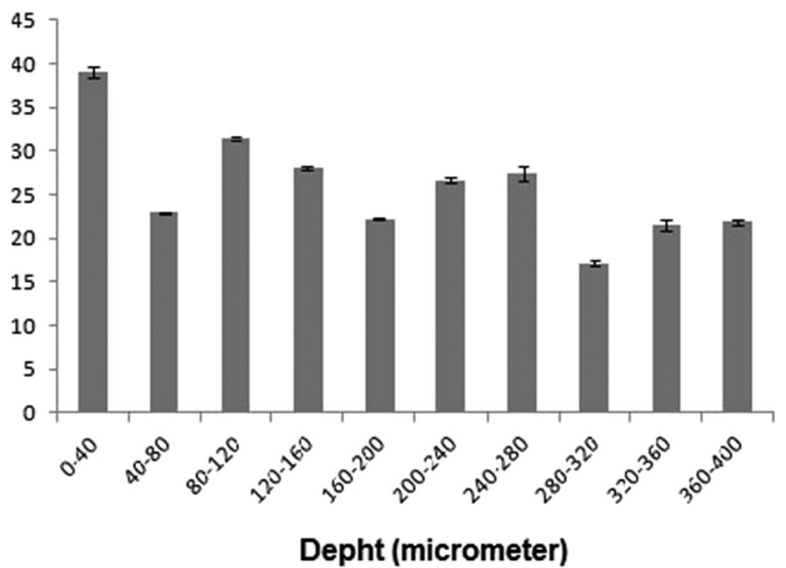

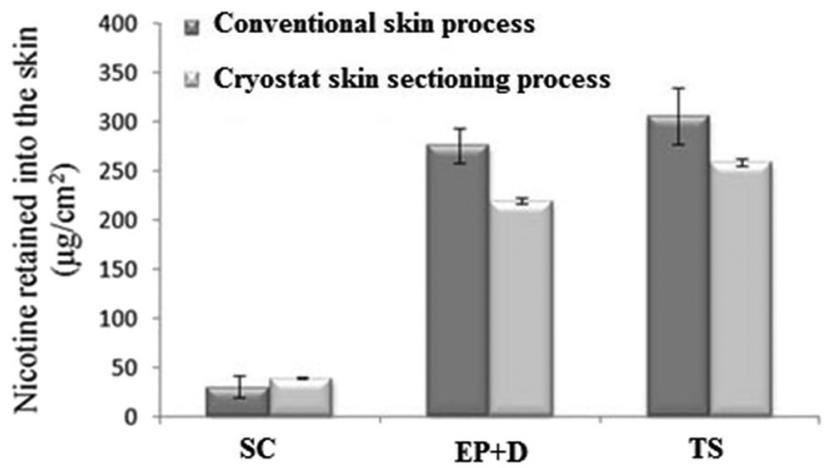

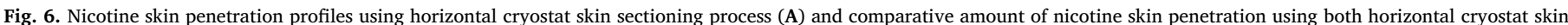

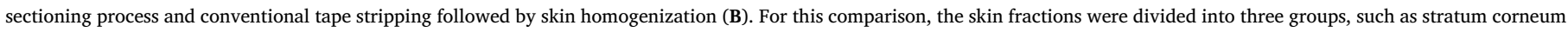

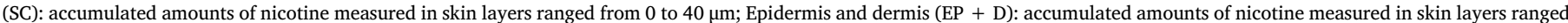

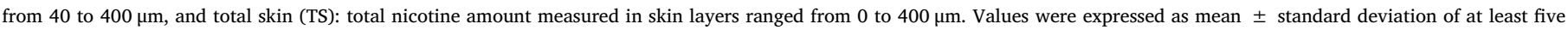
experiments. 
models for in vitro permeation studies (Jung and Maibach, 2015; Herkenne et al., 2006; Dick and Scott, 1992). Although no significant difference was observed in the cumulative amount of permeated hydrophilic nicotine and lipophilic estradiol after $8 \mathrm{~h}$ of permeation study (Fig. 1), at shorter times (2 to $6 \mathrm{~h}$ ) significant differences were observed between skin models mainly when nicotine was used. This suggests that the permeation barrier no longer becomes a critical factor for permeation rate after $8 \mathrm{~h}$, and these biological membranes can be used interchangeably. Curiously, similar permeation rates between the snake skin and human SC were observed in studies performed by Ngawhirunpat et al. (2006) and Pongjanyakul et al. (2000), suggesting the use of snake skin as another model membrane for permeation studies.

We also evaluated the skin storage conditions, i.e., the influence of skin freezing with and without cryoprotectant agent on skin integrity by transepidermal water loss (TEWL), skin electrical resistance, skin permeation/penetration rates and skin histological changes. Several investigators have attempted to use the skin electrical resistance and TEWL as indicators of skin normal condition (European Medicines Agency, 2014; Tang et al., 2001). Herein, the fresh skin samples showed significantly higher electrical resistance and variable TEWL compared to all other frozen skin samples (Fig. 2F), revealing that the cryoprotectant agent was not able to protect the barrier effect of frozen skin. Histological evaluation revealed the shrinkage of the epidermis layer (Fig. 2- B to E), suggesting that freezing damage did not disrupt the SC or tore the epidermis and dermis layers, but rather promoted a partial detachment of corneocytes, and thus caused a higher permeability of the tissue. Richters et al. (1996) showed that the structural integrity of the skin was well preserved after skin treatment with $10 \%$ glycerol solution. However, some parts of the treated skin showed shrinkage of keratinocytes. The authors explained that the glycerol skin preservation process led to shrinkage of cells. Glycerol as a cryoprotectant agent has been used in routine procedures with skin, cartilage, bone marrow and sperm to preserve structural aspects of biological samples with the aim of blocking or slowing down the cellular functions. The cell damage usually occurs for temperatures above 37 or less than $-196{ }^{\circ} \mathrm{C}$, when the intracellular water is lost associated with the increase of electrolytes concentration in intra/extracellular media, followed by ice crystal formation, deforming the cells. Therefore, the use of $10 \%$ glycerol in saline solution with samples stored at $-20{ }^{\circ} \mathrm{C}$ keeps isotonic conditions and glycerol binds with water through hydrogen bonds tending to prevent the nucleation and the formation of high concentration of ice crystals due to the maintenance of a liquid state and lower point of fusion. However, there is not a full understanding of the action mechanism of glycerol in cryopreservation, but it is classified as a diffusible and intracellularly active cryoprotectant (Bakhach, 2009). In addition, Björklund et al. (2013) explored the influence of glycerol at 7 to $30 \%$ on the in vitro permeability of excised skin membranes and the molecular structure of SC at varying hydrating conditions. A hydrophilic model drug (metronidazole, $\mathrm{Mz}$ ) presented similar steady state flux values and drug transport across skin membranes when water-based formulations containing glycerol or phosphate buffer saline were employed. These results demonstrated that the addition of glycerol to water-based transdermal formulations lowers the water activity without decreasing the skin permeability of Mz. Furthermore, pretreatment of the SC with water or glycerol results in similar structural features of the SC, regarding its lipid and protein components (Björklund et al., 2013). Thus, the protocol used in our study reflects the best levels of preservation reported for glycerol concentrations of 10 to $20 \%$ with slow cooling speed of skin samples (Villalba et al., 1996) (Björklund et al., 2013).

Furthermore, we analyzed by fluorescence microscopy skin samples stored at different conditions. As a result, it was possible to observe the presence of fluorescence in deeper layers of the skin $(E P+D)$ in all frozen membranes, while fresh skin samples showed fluorescence limited to superficial layers of the skin (SC), as shown in Fig. 3-B. Similarly, higher amounts of fluorescein permeated through frozen skin compared to fresh skin (Fig. 3-G). It is also important to consider that the indiscriminate use of skin (fresh or frozen) will certainly result in high standard deviation. Ahlstrom et al. (2007) studied the effect of freezing canine skin, without the glycerol skin preservation process, on the penetration rate of hydrocortisone (Ahlstrom et al., 2007). The skin samples were compared immediately after extraction and after freezing for 1 to 12 months. These authors observed similar results compared to our findings, suggesting that the freezing procedure and the extension of freezing time can significantly increase the transdermal drug penetration (Ahlstrom et al., 2007). Considering all qualitative and quantitative results obtained herein, skin freezing affects the topical and/or transdermal delivery regardless the use of a cryoprotectant agent probably due to reduction in the barrier function, as demonstrated by the reduction in the electrical resistance of the skin, increased TEWL and higher penetration/permeation. Based on these findings, we discourage the use of frozen porcine ear skin for in vitro permeation studies. Nevertheless, we recommend that all skin samples should be submitted to the same storage conditions whenever it is not possible fresh skin should be used in order to standardize and minimize any errors.

Concerning nicotine recovery studies, we first showed the importance of validating and standardizing the tape stripping technique. Thus, we evaluated three different protocols of pressure application in tape stripping by using operator finger, a roller or a constant weight ( $2 \mathrm{~kg}$, resulting in $349.3 \mathrm{~g} / \mathrm{cm}^{2}$ pressure). Different results were obtained for distribution of corneocytes removed; weight of SC removed; amount of protein removed by individual adhesive tapes, and total protein removed from 20 strips (Fig. 4). In particular, the application of finger pressure showed the ability to remove higher mass of the SC layer. Although it is more laborious and uncomfortable to perform in laboratory routine, it showed to be advantageous besides being cheaper compared to other procedures. Our results are in accordance with those showed by Löffler et al. (2004), who also demonstrated that the tape stripping procedure should be standardized in order to achieve reliable and reproducible results. In that study, the authors used tapes striped on several anatomical sites (forearm, forehead and back) from eight healthy volunteers while we used porcine ear skin, and consequently, the number of cells layers of the selected tissue and the thickness of SC had a similar distribution in our experiments. Conversely, the roller pressure applied on tape stripping technique is widely performed for in vivo dermatopharmacokinetics studies in patients (Lademann et al., 2009; Herkenne et al., 2006).

Subsequently, we evaluated the influence of two different vehicles on skin, such as sodium phosphate buffer (hydrophilic solution) and propylene glycol (less hydrophilic solution) by tape stripping technique applied immediately and $1 \mathrm{~h}$ after the end of permeation study $(24 \mathrm{~h})$. The bench time of $1 \mathrm{~h}$ (leaving the skin on absorbent paper) was proposed to observe if the skin would lose excess water and reorganize its structure after this period, increasing the tape stripping efficiency. In fact, long times used for in vitro skin permeation studies are able to promote high degree of skin hydration and possible disruption of this biological material losing its barrier function. OECD 428 Guidance's protocols suggest a maximum study time at about $24 \mathrm{~h}$. However, it is known that physicochemical characteristics of the vehicle used in permeation studies can promote a reversible disruption of the skin layers within this time decreasing the efficiency of tape stripping process. In other words, it is believed that immediately after in vitro permeation studies ( $24 \mathrm{~h}$ post application), the skin can be on advanced hydration state in which the removal of SC by adhesive tapes is hindered. Under macroscopic observations, bench time of $1 \mathrm{~h}$ was able to improve the tape stripping technique and avoid removing parts of the epidermal layer in the adhesives tapes when a hydrophilic vehicle was used (Fig. 5).

The recovery of penetrated drug from SC using adhesive tape is a simple procedure that requires specific extraction solvents (OECD, 2004). Hydrophobic drugs can be extracted using methanolic solution 
or similar organic solvents, whereas hydrophilic drugs can be extracted using aqueous solutions such as buffer solutions. A mixture of organic solvent and water solution followed by stirring and/or ultrasonic water bath are able to obtain high rates of both hydrophobic and hydrophilic drugs recovery from SC. Praça et al. (2011) obtained 98\% of celecoxib recovery from SC using a mixture of methanol and water $(75: 25, \mathrm{v} / \mathrm{v})$ while more hydrophobic vitamin $\mathrm{K}$ was $85 \%$ recovered from SC using $100 \%$ of methanol (Lopes et al., 2007). Considering drug recovery from $\mathrm{EP}+\mathrm{D}$, critical procedures can occur when $\mathrm{EP}+\mathrm{D}$ are processed as a homogenate. Herein, optimized drug extraction process from EP + D was developed and validated comparing the effect of extraction solvents with different polarities as well as ultrasound water bath time and the use of tissue cutter (Table 1). The optimized procedure using $4 \mathrm{~mL}$ of $100 \mathrm{mM}$ phosphate buffer ( $\mathrm{pH} 7.4$ ) as extraction solvent followed by homogenization in a tissue cutter at $2500 \mathrm{rpm}$ for $2 \mathrm{~min}$ and incubation in ultrasound water bath for $30 \mathrm{~min}$ was able to reach the highest recovery percentages of nicotine from different skin layers (about 100\%). The use of tissue cutter improved nicotine extraction 1.2 fold higher. Although similar nicotine recovery rates were observed using acetonitrile and phosphate buffer solution, the buffer solution was selected considering its capacity of drug solubility, lower cost and lack of toxicity.

Several drugs can be easily extracted from the skin samples and monitored by high performance liquid chromatography (HPLC) methods whenever suitable protocols are strictly validated. Thus, we presented a series of protocols for drug recovery from skin samples in Table 2, showing recovery rates around $100 \%$. All these protocols were developed by our research group over the last years. All steps used to quantify drug recovery were considered, such as specific skin area and skin layers used; extraction solvents; use of tissue cutter and/or vortex agitation/centrifugation/ultrasound water bath period. For example, lipoic acid was assessed by an HPLC system equipped with an electrochemical detector (whereas UV detector was used for all other assays). In most cases, a RP-C18 chromatographic column was used. Selectivity of HPLC methods was always verified in the presence of potentially interfering molecules, such as mobile phase, extraction solvent, skin solution homogenate and adhesives tapes. The methods that did not present any interfering peaks at the main retention time were considered to present acceptable selectivity. As a rule, most methods use organic solvents or buffer solution for drug extraction from skin associated with ultrasound water bath to disrupt the cell membrane and release the drug. The volume of the extraction solvent should be as low as possible in order to obtain a drug amount above the detection limit of the analytical method. Nevertheless, this minimum volume must be enough to submerge the stripped adhesive tapes (SC samples) as well as to cover the paddle of tissue homogenizer (EP + D samples). Furthermore, care must be taken during the step of spiking samples. Both adhesive tapes containing SC and remaining tissue $(\mathrm{EP}+\mathrm{D})$ should be

Table 2

Summarized protocols of skin penetration/recovery studies for several drugs

stratum corneum (SC); epidermis and dermis (EP + D); total skin (TS).

\begin{tabular}{|c|c|c|c|c|c|c|c|c|c|c|}
\hline Drug/active & $\begin{array}{l}\text { Skin } \\
\text { area } \\
\left(\mathrm{cm}^{2}\right)\end{array}$ & $\begin{array}{l}\text { Skin } \\
\text { tissue }\end{array}$ & Extraction solvent & $\begin{array}{l}\text { Volumes of } \\
\text { solvent } \\
\text { extraction (mL) }\end{array}$ & $\begin{array}{l}\text { Vortex } \\
\text { agitation } \\
(\mathrm{min})\end{array}$ & $\begin{array}{l}\text { Tissue } \\
\text { cutter } \\
(\mathrm{min})\end{array}$ & $\begin{array}{l}\text { Ultrasound bath } \\
\text { period (min) }\end{array}$ & Centrifugation & $\begin{array}{l}\text { Drug/ } \\
\text { active } \\
\text { recovery }\end{array}$ & Reference \\
\hline Celecoxib & 1.77 & $\begin{array}{l}\text { SC } \\
\mathrm{EP} \\
+\mathrm{D}\end{array}$ & $\begin{array}{l}\text { Methanol: water } \\
(70: 30)\end{array}$ & 3.0 & 1.0 & - & $\begin{array}{l}30.0(\mathrm{SC}) 15.0 \\
(\mathrm{EP}+\mathrm{D})\end{array}$ & $\begin{array}{l}1000 \times g \\
5.0 \min (\mathrm{SC}) \\
3.0 \min (\mathrm{EP}+\mathrm{D})\end{array}$ & $\begin{array}{l}91.3 \%(\mathrm{SC}) \\
98 \%(\mathrm{EP} \\
+\mathrm{D})\end{array}$ & $\begin{array}{l}\text { (Praça et al., } \\
\text { 2011) }\end{array}$ \\
\hline Tretinoin & 0.68 & $\begin{array}{l}\text { SC } \\
\text { EP } \\
+\mathrm{D}\end{array}$ & Tetrahydrofuran $70 \%$ & $\begin{array}{l}5.0(\mathrm{SC}) \\
1.0(\mathrm{EP}+\mathrm{D})\end{array}$ & 2.0 & - & 20.0 & - & $\begin{array}{l}62.4 \%(\mathrm{SC}) \\
65 \%(\mathrm{EP} \\
+\mathrm{D})\end{array}$ & $\begin{array}{l}\text { (Ascenso } \\
\text { et al., 2014) }\end{array}$ \\
\hline Vitamin $\mathrm{K}$ & 1.77 & $\begin{array}{l}\text { SC } \\
\text { EP } \\
+D\end{array}$ & Methanol & $\begin{array}{l}5.0(\mathrm{SC}) \\
2.0(\mathrm{EP}+\mathrm{D})\end{array}$ & 2.0 & - & 30.0 & - & $\begin{array}{l}>85 \% \\
\text { (TS) }\end{array}$ & $\begin{array}{l}\text { (Lopes et al., } \\
\text { 2007) }\end{array}$ \\
\hline Lycopene & 0.68 & TS & $\begin{array}{l}\text { Acetonitrile: methanol } \\
\text { (50:50, v:v) }\end{array}$ & 1.0 & 2.0 & - & 20.0 & $\begin{array}{l}2500 \mathrm{rpm} \\
10 \mathrm{~min}\end{array}$ & $64 \%$ & $\begin{array}{l}\text { (Ascenso } \\
\text { et al., 2013) }\end{array}$ \\
\hline Genistein & 1.86 & $\begin{array}{l}\mathrm{EP} \\
+\mathrm{D}\end{array}$ & Methanol & 5.0 & - & 2.0 & 20.0 & - & $96 \%$ & - \\
\hline Dexamethasone & 0.68 & $\begin{array}{l}\text { SC } \\
\text { EP } \\
+\mathrm{D}\end{array}$ & Methanol & $\begin{array}{l}4.0(\mathrm{SC}) \\
3.0(\mathrm{EP}+\mathrm{D})\end{array}$ & 2.0 & $\begin{array}{l}1.0(\mathrm{EP} \\
+\mathrm{D})\end{array}$ & 30.0 & - & $\begin{array}{l}96 \%(\mathrm{SC}) \\
85 \%(\mathrm{EP} \\
+\mathrm{D})\end{array}$ & - \\
\hline Vitamin E & 0.68 & $\begin{array}{l}\text { SC } \\
\text { EP } \\
+D\end{array}$ & Methanol & $\begin{array}{l}3.0(\mathrm{SC}) \\
5.0(\mathrm{EP}+\mathrm{D})\end{array}$ & 1.0 & - & 15.0 & $\begin{array}{l}400 \times g \\
5 \mathrm{~min}\end{array}$ & $\begin{array}{l}>80 \% \\
\text { (TS) }\end{array}$ & $\begin{array}{l}\text { (Ascenso } \\
\text { et al., 2015) }\end{array}$ \\
\hline Caffeine & 0.68 & $\begin{array}{l}\text { SC } \\
\text { EP } \\
+\mathrm{D}\end{array}$ & $\begin{array}{l}\text { Water: Methanol } \\
(60: 40)\end{array}$ & $\begin{array}{l}3.0(\mathrm{SC}) \\
5.0(\mathrm{EP}+\mathrm{D})\end{array}$ & 1.0 & - & 15.0 & $\begin{array}{l}400 \times g \\
5 \mathrm{~min}\end{array}$ & $\begin{array}{l}>80 \% \\
\text { (TS) }\end{array}$ & $\begin{array}{l}\text { (Ascenso } \\
\text { et al., 2015) }\end{array}$ \\
\hline Lipoic acid & 0.68 & $\begin{array}{l}\mathrm{EP} \\
+\mathrm{D}\end{array}$ & Acetonitrile & 6.0 & 1.0 & 1.0 & 15.0 & $\begin{array}{l}1360 \times g \\
5 \mathrm{~min}\end{array}$ & $73 \%$ & $\begin{array}{l}\text { (Campos } \\
\text { et al., 2016) }\end{array}$ \\
\hline Solamargine & 1.77 & $\begin{array}{l}\text { SC } \\
\text { EP } \\
+D\end{array}$ & Methanol & 3.0 & 1.0 & - & 30.0 & $\begin{array}{l}3125 \times g \\
10 \mathrm{~min}\end{array}$ & $\begin{array}{l}97 \%(\mathrm{SC}) \\
89 \%(\mathrm{EP} \\
+\mathrm{D})\end{array}$ & $\begin{array}{l}\text { (Tiossi et al., } \\
\text { 2014) }\end{array}$ \\
\hline Solasonine & 1.77 & $\begin{array}{l}\text { SC } \\
\text { EP } \\
+\mathrm{D}\end{array}$ & Methanol & 3.0 & 1.0 & - & 30.0 & $\begin{array}{l}3125 \times g \\
10 \mathrm{~min}\end{array}$ & $\begin{array}{l}97 \%(\mathrm{SC}) \\
92 \%(\mathrm{EP} \\
+\mathrm{D})\end{array}$ & $\begin{array}{l}\text { (Tiossi et al., } \\
\text { 2014) }\end{array}$ \\
\hline Cyclosporin A & 1.77 & $\begin{array}{l}\text { SC } \\
\text { EP } \\
+D\end{array}$ & Methanol & $\begin{array}{l}5.0(\mathrm{SC}) \\
2.0(\mathrm{EP}+\mathrm{D})\end{array}$ & 2.0 & - & 30.0 & - & $\begin{array}{l}89 \%(\mathrm{SC}) \\
93 \%(\mathrm{EP} \\
+\mathrm{D})\end{array}$ & $\begin{array}{l}\text { (Lopes et al., } \\
\text { 2006) }\end{array}$ \\
\hline $\begin{array}{l}\text { Nitrate of } \\
\quad \text { isoconazole }\end{array}$ & 1.77 & $\begin{array}{l}\mathrm{EP} \\
+\mathrm{D}\end{array}$ & Acetonitrile & 3.0 & 1 & - & 15.0 & - & $93 \%$ & - \\
\hline PpIX & 0.78 & $\begin{array}{l}\text { SC } \\
\text { EP } \\
+\mathrm{D}\end{array}$ & Dimethylsulfoxide & 4.0 & 2.0 & - & 30.0 & - & $\begin{array}{l}94 \%(\mathrm{SC}) \\
96 \%(\mathrm{EP} \\
+\mathrm{D})\end{array}$ & $\begin{array}{l}\text { (Rossetti } \\
\text { et al., 2016) }\end{array}$ \\
\hline Ketoprofen & 0.78 & $\begin{array}{l}\text { SC } \\
\text { EP } \\
+\mathrm{D}\end{array}$ & Methanol & 3.0 & 1.0 & 3.0 & 15.0 & - & $\begin{array}{l}>90 \% \\
\text { (TS) }\end{array}$ & - \\
\hline
\end{tabular}


spiked using a low volume of standard drug solution at a known concentration (maximum $50 \mu \mathrm{L}$ ) in order to avoid the contact of this solution with the glass tube. Higher volumes can be easily spilled from the tube before the drying process, and consequently, a significant drug loss will occur during the extraction process.

Finally, skin horizontal sectioning has been used for in vitro quantitative and qualitative methods for detecting fluorescent drugs and labeled nanoparticles retained into specific skin layers (Praça et al., 2012). This technique enables the separation of the epidermis from the dermis by micrometric fractions (Lademann et al., 2009). Herein, we obtained a series of micrometric horizontal fractions of both epidermis (including SC) and dermis after in vitro permeation study in order to map the nicotine distribution from the upper to lower skin layers (Fig. 6-A). These results were compared with those obtained using conventional tape stripping followed by EP + D homogenization. Our findings demonstrated that a similar amount of nicotine was present in each $40 \mu \mathrm{m}$ of skin, suggesting that nicotine was partitioned in all skin layers. The amount of nicotine retained into the SC and EP + D using both techniques was quite comparable considering the skin thickness (Fig. 6-B). Thus, there is a possible interchangeability between these methods to determine retained drug into the skin.

\section{Conclusion}

Although in vitro drug permeation/penetration studies are numerous in the literature, most of them are subject to a great variability, posing a challenge to method standardization and verification of reproducibility. Herein, we successfully addressed different parameters for in vitro skin studies that certainly affect drug permeation and penetration, such as the animal skin source, the protocol variables for tape stripping, and the possibility of using cryostat sectioning of frozen skin as an alternative method for SC removal. From our results, it was evident that snake skin could be a substitute for porcine ear and mouse skins, which are more commonly employed. However, special care must be taken regarding the hydration of this tissue. We also demonstrated that the best method for tape stripping is the application of finger pressure, leading to better SC removal. Moreover, the use of less hydrophilic vehicles such as propylene glycol in these experiments might result in better SC removal by the tape stripping. Finally, we showed herein that the sectioning of the skin using the cryostat might be a substitute for the commonly used tape stripping method, achieving reliable results in terms of drug quantification in the different layers of skin. In general, our results suggest that a careful standardization and validation of the protocols for in vitro skin studies should be carried out prior to the experiments for obtaining reliable data. We expect that these findings might be an important contribution for future studies on skin drug delivery, hoping that researchers could achieve more reproducible and reliable results following our recommendations.

\section{Acknowledgements}

This work was supported by São Paulo Research Foundation (FAPESP, Brazil, Project \#04/09465-7 and Project \#2013/16617-1), National Council for Scientific and Technological Development (CNPq) and Ministry of Science and Technology (MCT-CAPES). The authors thank Dr. Renata Fonseca Vianna Lopes and Dr. Patricia Maria Gonçalves Maia Campos for some lab facilities.

\section{References}

Ahlstrom, L.A., Cross, S.E., Mills, P.C., 2007. The effects of freezing skin on transdermal drug penetration kinetics. J. Vet. Pharmacol. Ther. 30 (5), 456-463. http://dx.doi. org/10.1111/j.1362-2885.2007.00879.x.

Ascenso, A., Pinho, S., Eleutério, C., Praça, F.G., Bentley, M.V.L.B., Oliveira, H., Santos, C., Silva, O., Simões, S., 2013. Lycopene from tomatoes: vesicular nanocarrier formulations for dermal delivery. J. Agric. Food Chem. 61, 7284-7293. http://dx.doi. org/10.13140/2.1.3833.9524.
Ascenso, A., Salgado, A., Euletério, C., Praça, F.G., Marques, H.C., Oliveira, H., Santos, C., Simões, S., 2014. In vitro and in vivo topical delivery studies of tretinoin-loaded ultradeformable vesicles. Eur. J. Pharm. Biopharm. 88, 48-55. http://dx.doi.org/10. 1016/j.efpb.2014.05.002.

Ascenso, A., Raposo, S., Batista, C., Cardoso, P., Mendes, T., Praça, F.S., Bentley, M.V.L.B., Simões, S., 2015. Development, characterization, and skin delivery studies of related ultradeformable vesicles: transfersomes, ethosomes, and transethosomes. Int. J. Nanomedicine 10, 5837-5851. http://dx.doi.org/10.2147/ijn.s86186.

Babu, R.J., Kanikkannan, N., Kikwai, L., Ortega, C., Andega, S., Ball, K., Yim, S., Singh, M., 2003. The influence of various methods of cold storage of skin on the permeation of melatonin and nimesulide. J. Control. Release 86 (1), 49-57. http://dx.doi.org/10. 1016/S01683659(02)003681.

Baby, A.R., Lacerda, A.C.L., Velasco, A.V.R., Lopes, P.S., Kawano, Y., Kaneko, T.M., 2006. Spectroscopic studies of stratum corneum model membrane from Bothrops jararaca treated with cationic surfactant. Colloids Surf., B 50 (1), 61-65. http://dx.doi.org/10. 1016/J.COLSURFB.2006.04.005.

Baby, A.R., Lacerda, A.C., Kawano, Y., Velasco, M.V., Kaneko, T.M., 2007. PAS FTIR and FT Raman qualitative characterization of sodium dodecyl sulfate interaction with an alternative stratum corneum model membrane. Pharmazie 62 (10), 727-731.

Baby, A.R., Haroutiounian-Filho, C.A., Sarruf, F.D., Tavante-Júnior, C.R., Pinto, C.A.S.O., Zague, V., Arêas, E.P.G., Kaneko, T.M., Velasco, M.V.R., 2008. Estabilidade e estudo de penetração cutânea in vitro da rutina veiculada em uma emulsão cosmética através de um modelo de biomembrana alternativo. Braz. J. Pharm. Sci. 44 (2), 233-248. http://dx.doi.org/10.1590/s1516-93322008000200009.

Bakhach, J., 2009. The cryopreservation of composite tissue. Principles and recent advances on cryopreservation of different type of tissues. Organ 5 (3), 119-126.

Barbero, A.M., Frasch, H.F., 2009. Pig and guinea pig skin as surrogates for human in vitro penetration studies: a quantitative review. Toxicol. in Vitro 23 (1), 1-13. http:// dx.doi.org/10.1016/j.tiv.2008.10.008.

Björklund, S., Engblom, J., Thuresson, K., Sparr, E., 2013. Glycerol and urea can be used to increase skin permeability in reduced hydration conditions. Eur. J. Pharm. Sci. 50 (5), 638-645. http://dx.doi.org/10.1016/j.ejps.2013.04.022.

Bravo, D., Rigley, T.H., Gibran, N., Strong, D.M., Newman-Gage, H., 2000. Effect of storage and preservation methods on viability in transplantable human skin allografts. Burns 26 (4), 367-378. http://dx.doi.org/10.1016/S0305-4179(9)00169-2.

Bronaugh, R.L., Stewart, R.F., 1985. Methods for in vitro percutaneous absorption studies IV: the flow-through diffusion cell. J. Pharm. Sci. 74, 64-67. http://dx.doi.org/10. 1002/jps.2600740117.

Campos, P.M., Praça, F.S.G., Bentley, M.V.L.B., 2016. Quantification of lipoic acid from skin samples by HPLC using ultraviolet, electrochemical and evaporative light scattering detectors. J. Chromatogr. B 1019, 66-71. http://dx.doi.org/10.1016/j. jchromb. 2015.07.029.

De Paula, D., Oliveira, D.C.R., Tedesco, A.C., Bentley, M.V.L.B., 2007. Enhancing effect of modified beta-cyclodextrins on in vitro skin permeation of estradiol. Braz. J. Pharm. Sci. 43 (1), 111-120. http://dx.doi.org/10.1590/S1516-93322007000100014.

Debeer, S., Luduec, J.B., Le, Kaiserlian D., Laurent, P., Nicolas, J.F., Dubois, B., Kanitakis, J., 2013. Comparative histology and immunohistochemistry of porcine versus human skin. Eur. J. Dermatol. 23 (4), 456-466. http://dx.doi.org/10.1684/ejd.2013.2060.

Depieri, L.V., Praça, F.S.G., Campos, P.M., Bentley, M.V.L.B., 2015. Advances in the bioanalytical study of drug delivery across the skin. Ther. Deliv. 6 (5), 571-594. http://dx.doi.org/10.4155/tde.15.20.

Dick, I.P., Scott, R.C., 1992. Pig ear skin as an in vitro model for human skin permeability. J. Pharm. Pharmacol. 44, 640-645. http://dx.doi.org/10.1111/j.2042-7158.1992. tb05485.x.

Echevarria, L., Blanco-Pietro, M.J., Campanero, M.A., Santoyo, S., 2003. Development and validation of a liquid chromatographic method for in vitro mupirocin quantification in both skin layers and percutaneous penetration studies. J. Chromatogr. B 233-241. http://dx.doi.org/10.1016/j.jchromb.2003.07.011.

Estracanholli, E.A., Praça, F.S., Cintra, A.B., Pierri, M.B., Lara, M.G., 2014. Liquid crystalline systems for transdermal delivery of celecoxib: in vitro drug release and skin permeation studies. AAPS PharmSciTech 15 (6), 1468-1475. http://dx.doi.org/10. 1208/s12249-014-0171-2.

European Medicines Agency, 2014. Guideline on Quality of Transdermal Patches Table of Contents. 44. European Medicines Agency, pp. 1-28.

Fang, J.Y., Wu, P.C., Huang, Y.B., Tsai, Y.H., 1995. In vitro permeation study of capsaicin and its synthetic derivatives from ointment bases using various skin types. Int. J. Pharm. 126 (1-2), 119-128. http://dx. doi.org/10.1016/0378-5173(95)04105-2.

Godin, B., Touitou, E., 2007. Transdermal skin delivery: predictions for humans from in vivo, ex vivo and animal models. Adv. Drug Deliv. Rev. 59 (11), 1152-1161. http:// dx.doi.org/10.1016/j.addr.2007.07.004.

Gould, D., 2016. Quantitative Assay for Fluorescein. Organic Chemistry Labs. http:// www.odinity.com/quantitative-assay-fluorescein/.

Haigh, J.M., Smith, E.W., 1994. The selection and use of natural and synthetic membranes for in vitro diffusion experiments. Eur. J. Pharm. Sci. 2, 311-330. http://dx.doi.org/ 10.1016/0928-0987(94)90032-9.

Haigh, J.M., Beyssac, E., Chanet, L., Aiache, J.M., 1998. In vitro permeation of progesterone from a gel through the shed skin of three different snake species. Int. J. Pharm. 170, 151-156. http://dx.doi.org/10.1016/s0378-5173(98)00064-7.

Herkenne, C., Naik, A., Kaila, Y.N., Hadgraft, J., Guy, R., 2006. Pig ear skin ex vivo as a model for in vivo dermatopharmacokinetic studies in man. Pharm. Res. 23 (8), 1850-1856. http://dx.doi.org/10.1007/s11095-006-9011-8.

Herron, A.J., DVM, 2009. Pigs as Dermatologic Models of Human Skin Disease. Proceeding of the ACVP/ASVCP Concurrent Annual Meetings December 5-9, Monterey, California, USA.

Hirvonen, J., Rytting, J.H., Paronen, P., Urtti, A., 1991. Dodecyl N,N-dimethylamino acetate and azone enhance drug penetration across human, snake, and rabbit skin. 
Pharm. Res. 8 (7), 933-937. http://dx.doi.org/10.1023/A:1015824100788.

Itoh, T., Magavi, R., Casady, R.L., Nishihata, T., Rytting, J.H., 1990a. A method to predict the percutaneous permeability of various compounds: shed snake skin as a model membrane. Pharm. Res. 7, 1302-1306. http://dx.doi.org/10.1023/ A:1015902308676.

Itoh, T., Xia, J., Magavi, R., Casady, R.L., Nishihata, T., Rytting, J.H., 1990b. Use of shed snake skin as a model membrane for in vitro percutaneous penetration studies: comparison with human skin. Pharm. Res. 7 (10), 1042-1047. http://dx.doi.org/10. 1023/A:1015943200982.

Jung, E.C., Maibach, H.I., 2015. Animal models for percutaneous absorption. J. Appl. Toxicol. 35 (1), 1-10. http://dx.doi.org/10.1002/jat.3004.

Labouta, H.I., Kraus, T., El-Khordaqui, L.K., Schneider, K., 2011. Combined multiphoton imaging-pixel analysis for semiquantitation of skin penetration of gold nanoparticles. Int. J. Pharm. 413 (1-2), 279-282. http://dx.doi.org/10.1016/j.ijpharm.2011.03. 067.

Lademann, J., Jacobi, U., Surber, C., Weigmann, H.J., Fluhr, J.W., 2009. The tape stripping procedure - evaluation of some critical parameters. Eur. J. Pharm. Biopharm. 72 (2), 317-323. http://dx.doi.org/10.1016/j.ejpb.2008.08.008.

Liangpeng, G.E., Huang, Z., Wei, H., 2011. Skin graft preservation. In: Spear, Marcia (Ed.), Skin Grafts - Indications, Applications, and Current Research, pp. 159-175. http://dx.doi.org/10.5772/23084.

Lindemann, U., Weigmann, H.J., Schaefer, H., Sterry, W., Lademann, J., 2003. Evaluation of the pseudo-absorption method to quantify human stratum corneum removed by tape stripping using protein absorption. Skin Pharmacol. Appl. Skin Physiol. 16 (4), 228-236 DOI: 70845.

Löffler, H., Dreher, F., Maibach, H.I., 2004. Stratum corneum adhesive tape stripping: influence of anatomical site, application pressure, duration and removal. Br. J. Dermatol. 151 (4), 746-752. http://dx.doi.org/10.1111/j.1365-2133.2004.06084x.

Lopes, L.B., Ferreira, D.A., de Paula, D., Garcia, M.T., Thomazini, J.A., Fantini, M.C., Bentley, M.V., 2006. Reverse hexagonal phase nanodispersion of monoolein and oleic acid for topical delivery of peptides: in vitro and in vivo skin penetration of cyclosporin A. Pharm. Res. 23 (6), 1332-1342. http://dx.doi.org/10.1007/s11095-0060143-7.

Lopes, L.B., Speretta, F.F.F., Bentley, M.V.L.B., 2007. Enhancement of skin penetration of vitamin K using monoolein-based liquid crystalline systems. Eur. J. Pharm. Sci. 32 (3), 209-215. http://dx.doi.org/10.1016/j.ejps.2007.07.006.

Mahl, J.A., Vogel, B.E., Court, M., Kolopp, M., Roman, D., Nogues, V., 2006. The minipig in dermatotoxicology: methods and challenges. Exp. Toxicol. Pathol. 57 (5-6), 341-345. http://dx.doi.org/10.1016/j.etp.2006.03.004.

Meurens, F., Summerfield, A., Nauwynck, H., Saif, L., Gerdts, V., 2012. The pig: a model for human infectious diseases. Trends Microbiol. 20 (1), 50-57. http://dx.doi.org/10. 1016/j.tim.2011.11.002.

Ngawhirunpat, T., Panomsuk, S., Opanasopit, P., Rojanaraba, T., Hatanaka, T., 2006. Comparison of the percutaneous absorption of hydrophilic and lipophilic compounds in shed snake skin and human skin. Pharmazie 61 (4), 331-335.

Nicolazzo, A.J., Reed, L.B., Finnin, B.C., 2003. The effect of various condictions on the permeability characteristics of the buccal mucosa. J. Pharm. Sci. 92 (12), 2399-2410. http://dx.doi.org/10.1002./jps.10505.

Nunes, R.S., Azevedo, J.R., Vasconcelos, A.P., Pereira, N.L., 2005. Estudo de padronização da pele de cobra espécie - Boa constrictor - como modelo de estrato córneo para permeação de fármacos. Scientia Plena 1 (7), 171-175.

OECD, Guideline 428, 2004. Skin absorption: in vitro method. In: Guidance Document for the Conduct of Skin Absorption Studies, Paris.

Pereira, G.R., Marchetti, J.M., Bentley, M.V.L.B., 2001. A simple and rapid method for nicotine assay by HPLC from cutaneous microdialysis samples. Anal. Lett. 34 (10), 1669-1676. http://dx.doi.org/10.1081/AL-100105350.

Petrilli, R., Praça, F.S., Carollo, A.R.H., Medina, W.S.G., Oliveira, T.K., Fantini, M.C.A., Neves, M.G.P.M.S., Cavaleiro, J.A.S., Serra, O.A., Iamamoto, Y., Bentley, M.V.L.B., 2013. Nanoparticles of lyotropic liquid crystals: a novel strategy for the topical delivery of a chlorine derivative for photodynamic therapy of skin cancer. Curr. Nanosci. 9 (5), 434-441. http://dx.doi.org/10.2174/1573413711309040003.
Petrilli, R., Eloy, J.O., Praça, F.S., Del Ciampo, J.O., Fantini, M.A., Fonseca, M.J., Bentley, M.V., 2016. Liquid crystalline nanodispersions functionalized with cell-penetrating peptides for topical delivery of short-interfering RNAs: a proposal for silencing a proinflammatory cytokine in cutaneous diseases. J. Biomed. Nanotechnol. 12 (5), 1063-1075. http://dx.doi.org/10.1166/jbn.2016.2211.

Pongjanyakul, T., Prakongpan, S., Priprem, A., 2000. Permeation studies comparing cobra skin with human skin using nicotine transdermal patches. Drug Dev. Ind. Pharm. 26 (6), 635-642. http://dx.doi.org/10.1081/DDC-100101278.

Praça, F.S.G., Bentley, M.V., Lara, M.G., Pierre, M.B., 2011. Celecoxib determination in different layers of skin by a newly developed and validated HPLC-UV method. Biomed. Chromatogr. 25 (11), 1237-1244. http://dx.doi.org/10.1002/bmc.1596.

Praça, F.S.G., Medina, M.S.G., Petrilli, R., Bentley, M.V.L.B., 2012. Liquid crystal nanodispersions enable the cutaneous delivery of photosensitizer for topical PDT: fluorescence microscopy study of skin penetration. Curr. Nanosci. 8 (4), 535-540. http:// dx.doi.org/10.2174/157341312801784203.

Qvist, M.H., Hoeck, U., Kreilgaard, B., Madsen, F., Frokjaer, S., 2000. Evaluation of Gottingen minipig skin for transdermal in vitro permeation studies. Eur. J. Pharm. Sci. 11 (1), 59-68. http://dx.doi.org/10.1016/S0928-0987(00)00091-9.

Richters, C.D., Hoekstra, M.J., van Baare, J., du Port, J.J., Kamperdijk, E.W., 1996. Morphology skin of glycerol-preserved human cadaver. Burns 22 (2), 113-116. http://dx.doi.org/10.1016/0305-4179(95)00103-4.

Rigg, P.C., Barry, B.W., 1990. Shed snake skin and hairless mouse skin as model membranes for human skin during permeation studies. J. Invest. Dermatol. 94 (2), 235-240. http://dx.doi.org/10.1111/1523-1747.ep12874561.

Rossetti, F.C., Depieri, L.V., Tedesco, A.C., Bentley, M.V.L.B., 2010. Fluorometric quantification of protoporphyrin IX in biological skin samples from in vitro penetration/ permeation studies. Braz. J. Pharm. Sci. 46 (4), 753-760. http://dx.doi.org/10.1590/ s1984-82502010000400017.

Rossetti, F.C., Depieri, L.V., Praça, F.G., Del Ciampo, J.O., Fantini, M.C., Pierre, M.B., Tedesco, A.C., Bentley, M.V., 2016. Optimization of protoporphyrin IX skin delivery for topical photodynamic therapy: nanodispersions of liquid-crystalline phase as nanocarriers. Eur. J. Pharm. Sci. 83, 99-108. http://dx.doi.org/10.1016/j.ejps.2015. 12.003.

Summerfield, A., Meurens, F., Meret, E., Ricklin, 2015. The immunology of the porcine skin and its value as a model for human skin. Mol. Immunol. 66 (1), 14-21. http://dx. doi.org/10.1016/j.molimm.2014.10.023.

Takahashi, K., et al., 2001. Influence of $\mathrm{pH}$ on the permeability of p-toluidine and aminopyrine through shed snake skin as a model membrane. Drug Dev. Ind. Pharm. 27 (2), 159-164. http://dx.doi.org/10.1081/DDC-100000482.

Tan, G., Xu, P., Lawson, L.B., He, J., Freytag, L.C., Clements, J.D., John, V.T., 2010. Hydration effects on skin microstructure as probed by high-resolution cryo-scanning electron microscopy and mechanistic implications to enhanced transcutaneous delivery of biomacromolecules. J. Pharm. Sci. 99 (2), 730-740. http://dx.doi.org/10. 1002/jps.21863.

Tang, H., Mitragotri, S., Blankschtein, D., Langer, R., 2001. Theoretical description of transdermal transport of hydrophilic permeants: application to low-frequency sonophoresis. J. Pharm. Sci. 90 (5), 545-568. http://dx.doi.org/10.1002/15206017(200105)90:5< 545::AID-JPS1012> 3.0CO:2-H.

Tiossi, R.F.J., Miranda, M.A., Praça, F.S., Mc Chesney, J.D., Bentley, M.V., 2014. In vitro and in vivo evaluation of the delivery of topical formulations containing glycoalkaloids of Solanum lycocarpum fruits. Eur. J. Pharm. Biopharm. 88, 28-33. http://dx. doi.org/10.1016/j.ejpb.2014.01.010.

Vecchia, B.E., Bunge, A.L., 2005. Animal models: a comparison of permeability coefficients for excised skin from humans and animals. In: Riviere, J.E. (Ed.), Dermal Absorption Models in Toxicology and Pharmacology. Taylor \& Francis Group, New York. http://dx.doi.org/10.1201/9780203020821.

Villalba, R., Benitez, J., de No-Lowis, E.D., Rioja, L.F., Gomez-Villagran, J.L., 1996. Cryopreservation of human skin with propane-1,2-diol. Cryobiology 33 (5), 525-529. 8893511.

World Health Organization, 2006. Environmental Health Criteria 235: Dermal Absorption. http://www.who.int/ipcs/features/2006/ehc235/en/. 